\title{
Estudos de Saúde Mental publicados nos últimos 25 anos na Revista Ciência \& Saúde Coletiva
}

\author{
Mental Health Studies published in the last 25 years \\ in the Journal Ciência \& Saúde Coletiva
}

\author{
Rosana Onocko Campos (https://orcid.org/0000-0003-0469-5447) ${ }^{1}$ \\ Deivisson Vianna Dantas dos Santos (https://orcid.org/0000-0002-1198-1890) ${ }^{2}$ \\ Alberto Velzi Diaz (https://orcid.org/0000-0001-6304-2150) ${ }^{3}$ \\ Bruno Emerich (https://orcid.org/0000-0001-7246-5809) \\ Thiago Trape (https://orcid.org/0000-0002-5288-4966) ${ }^{4}$ \\ Carlos Alberto Pegolo da Gama (https://orcid.org/0000-0002-6345-7476) ${ }^{5}$ \\ Carlos Eduardo Menezes Amaral (https://orcid.org/0000-0002-1719-1080) ${ }^{6}$ \\ Rosana Evangelista Poderoso (https://orcid.org/0000-0001-8661-1168) ${ }^{1}$ \\ Ana Luiza Ferrer (https://orcid.org/0000-0003-0862-1015) ${ }^{7}$ \\ Lilian Miranda (http://orcid.org/0000-0002-8238-8111) ${ }^{8}$ \\ Mariana Barbosa Pereira (https://orcid.org/0000-0003-3276-9407) ${ }^{1}$ \\ Luciana Togni Surjus (https://orcid.org/0000-0002-3419-9797) ${ }^{1}$
}

${ }^{1}$ Faculdade de Ciências

Médicas, Universidade

Estadual de Campinas

(Unicamp). R. Tessália

Vieira de Camargo 126,

Barão Geraldo. 13084-

971 Campinas SP Brasil.

rosanaoc@unicamp.br

${ }^{2}$ Departamento de Saúde

Coletiva, Universidade

Federal do Paraná. Curitiba

PR Brasil.

${ }^{3}$ Consejo de Investigadores,

Universidad Nacional de

Rosario. Rosario Santa Fé

Argentina.

${ }^{4}$ Faculdade São Leopoldo

Mandic. Rio de Janeiro RJ

Brasil.

${ }^{5}$ Universidade Federal de

São João Del Rei. São João

Del Rei MG Brasil.

${ }^{6}$ Universidade Federal

do Vale do São Francisco.

Petrolina PE Brasil.

${ }^{7}$ Universidade Federal de

Santa Maria. Santa Maria

RS Brasil.

${ }^{8}$ Universidade Federal Rural

do Rio de Janeiro. Rio de

Janeiro RJ Brasil.

\begin{abstract}
A systematic review of the 25-year Mental Health production of Journal Ciência \& Saúde Coletiva was performed to identify whether this production had changed over time. We investigated whether these changes would have any relationship with the implementation of a new regulatory and legal framework for this field and the expansion of public services and the promotion of public funding agencies' investigation on the subject. A total of 278 original papers were analyzed from the following categories: sociocultural transformations related to madness and its approach; legislative changes; implantation, coverage range and operation of the network of substitute services; clinic/care developed in substitute services; the role and possibilities of primary care; drug use -related problems; mental health of children and adolescents; epidemiological studies/psychiatric categories; and others - which included ethnic-racial issues, violence, about the elderly population, suicide, bullying, and migration. A chronological relationship can be observed between the increase in publications and research notices and the expansion of services, not seemingly in the same way concerning care for people with alcohol and other drug problems.
\end{abstract}

Key words Mental health, Systematic review, Public health policy
Resumo Realizou-se revisão sistemática de 25 anos de produção da Revista Ciência er Saúde Coletiva sobre a temática de Saúde Mental buscando responder se essa produção tinha se modificado ao longo do tempo. Perguntou-se se essas mudanças guardariam alguma relação com a implementação de um novo marco regulatório e legal para essa área assim como com a expansão de serviços públicos e com os estímulos à investigação do tema por Agencias Públicas de financiamento. Analisaram-se 278 artigos originais, apresentados a partir das categorias: transformações socioculturais relacionadas à loucura e sua abordagem; mudanças legislativas; implantação, capilaridade e funcionamento da rede de serviços substitutivos; clínica/cuidado desenvolvido nos serviços substitutivos; o papel e as possibilidades da atenção básica; problemas relacionados ao uso de drogas; saúde mental de crianças e adolescentes; estudos epidemiológicos/categorias psiquiátricas; e outros - nas quais foram incluídas as questões étnico-raciais, de violência, acerca da população idosa, suicídio, bullying e migração. Pode ser observada relação cronológica entre o aumento de publicações e os editais de pesquisa e a expansão de serviços, não parecendo ser da mesma forma em relação ao tema dos cuidados a pessoas com problemas com álcool e outras drogas.

Palavras-chave Saúde mental, Revisão sistemática, Políticas públicas de saúde 


\section{Introdução}

A literatura internacional sobre a carga de doenças mentais nas sociedades contemporâneas aponta preocupante gap de mortalidade das pessoas com transtornos mentais ${ }^{1}$. A diminuição desse gap foi colocada pela Organização das Nações Unidas como um dos objetivos do milênio². Para isso, insta-se aos governos a diminuírem o estigma, a aumentarem o acesso aos serviços de saúde em geral e a vincularem aos serviços de saúde mental (SM), em particular.

Processos de reforma assistencial na SM foram desenvolvidos por inúmeros países ocidentais, com ritmos diferentes, porém com um rumo comum: a inclusão da SM como componente ineludível da saúde geral, a substituição dos hospitais monovalentes asilares por serviços comunitários e o investimento no recovery dos pacientes e no combate ao estigma ${ }^{3}$.

Os últimos 25 anos foram cenários de grandes mudanças institucionais e políticas no Brasil. Nesse período, o país também avançou em seu processo democrático. Muito jovem, em 1995, a democracia brasileira, depois de 7 eleições presidenciais, encara hoje um desafio inédito. $\mathrm{O}$ Sistema Único de Saúde (SUS) enfrentou desde seus primórdios crises de financiamento e de desenvolvimento regional, mesmo assim, é hoje a principal cobertura de saúde de $75 \%$ dos brasileiros ${ }^{4}$. A implementação de uma política pública de Saúde Mental (SM) tem sido responsável pelas mudanças nas concepções socioculturais sobre a loucura, com a instalação de novos serviços e reformas do modelo assistencial ${ }^{5}$.

A Reforma Psiquiátrica Brasileira teve nesse período um importante avanço. Fechamento de leitos asilares, abertura de novos serviços comunitários e aprovação da lei no 2.016, que em 2001 garantiu um marco jurídico para o processo. Contudo, houve também retrocessos nessa démarche após a crise institucional que derrubou a presidenta da República em $2016^{6}$. Considerando o período de análise, identificamos os principais acontecimentos em termos de direcionamento das políticas e de fomento ao desenvolvimento da ciência e tecnologia, a partir dos quais buscamos verificar se houve relação entre esses eventos e as publicações.

Nos anos 2000, 2002, 2010 e 2011 foram publicadas portarias que instituíram os Serviços Residenciais Terapêuticos (SRT), os Centros de Atenção Psicossocial (CAPS), em diferentes modalidades, e a Rede de Atenção Psicossocial (RAPS). Em 2001 ocorre a aprovação da Lei no 10.216 , que dispõe sobre a proteção e os direitos das pessoas portadoras de transtornos mentais e redireciona $o$ modelo assistencial em saúde mental, e a realização da $3^{a}$ Conferência Nacional de Saúde Mental. Especificamente, acerca da política sobre drogas, a Lei $n^{\circ} 11.343$, que cria o Sistema Nacional de Políticas Públicas sobre drogas, foi aprovada em 2006, em 2009 a Portaria que instituiu o Plano Emergencial de Ampliação do Acesso ao Tratamento e Prevenção em Álcool e outras Drogas e em 2010 o Decreto no 7.179 que cria o Programa de Enfrentamento ao Crack e a Portaria 2.841 que regulamenta o CAPS álcool e outras drogas tipo III (CAPSad III). Nos anos 2006, 2008 e 2009 foram publicados editais do Programa de Pesquisa para o SUS (PPSUS) Saúde Mental. A partir de 2016 são publicadas as Portarias no 1.482/2016 e $\mathrm{n}^{\circ} 3.588 / 2017$ que, respectivamente, incluem as Comunidades Terapêuticas no Cadastro Nacional de Estabelecimentos de Saúde e o ambulatório especializado, hospital-dia, hospital psiquiátrico e CAPS álcool e outras drogas tipo IV (CAPSad IV) na RAPS; além da Lei no 13.840/2019, que Reformula Sisnad e exclui redução de danos das diretrizes da Política sobre Drogas.

A Revista Ciência \& Saúde Coletiva, da Abrasco, veio ao longo desse período consolidando sua posição no campo, até se configurar hoje em uma das mais citadas e referenciadas da área da saúde coletiva no Brasil. Nesse marco, nos propusemos a fazer a seguinte pergunta guia para nossa revisão sistemática: Houve mudanças temáticas e metodológicas das publicações sobre SM na Revista Ciência \& Saúde Coletiva ao longo dos últimos 25 anos? Se sim, é possivel estabelecer alguma relação entre elas e as mudanças nos marcos regulatórios $e$ de estímulo à pesquisa? Como se configura o hoje o campo da SM na Saúde Coletiva Brasileira?

\section{Metodologia}

A busca pelos artigos foi realizada entre fevereiro e março de 2020, sendo considerados os trabalhos publicados na Revista Ciência \& Saúde Coletiva de 1999 a março de 2020. Para a busca dos artigos foram utilizados os descritores "CAPS or Centros de Atenção Psicossocial or Psychosocial Care Center"; "SM or Mental Health"; "Reforma Psiquiátrica or Psychiatric Reform"; "Reabilitação Psicossocial or Psychosocial Rehabilitation"; "Centros Comunitários de SM or Psychosocial Care Centers". Foram encontrados 585 artigos no SciELO e 349 no PubMed, somando 934. Inicialmente foram excluídos os trabalhos repetidos, 
restando 329 artigos. Numa segunda fase foi realizada uma busca pelo sumário da revista. Foram encontrados mais 32 artigos para análise, em sua maioria, relativos às questões de violência, saúde mental de crianças e adolescentes e problemas relacionados ao uso de drogas, totalizando 361 artigos. Na terceira fase da seleção, uma nova varredura visou excluir artigos que não respondiam às questões guia. Foram retirados 83 itens, chegando-se ao total de 278 artigos.

Os 278 artigos foram lidos e sistematizados em um quadro contendo dados de identificação: ano de publicação, nome do estudo, autores, instituição, estado das instituições, tipo de estudo, desenho, local de desenvolvimento da pesquisa, principais achados e conclusões. Essa sistematização foi realizada pelo conjunto dos pesquisadores e contou com validações on line. Artigos com dúvida sobre sua classificação foram relidos por mais de um pesquisador até chegar a um consenso (Figura 1). Os dados e análises obtidos são descritos a seguir.

\section{Resultados}

Em relação às temáticas específicas de saúde mental (Gráfico 1), artigos sobre levantamentos epidemiológicos de problemas mentais específicos e que versavam sobre transformações socioculturais relacionadas à loucura e à sua abordagem totalizaram 51 e 48 artigos, respectivamente. Estes, juntamente com os 43 artigos que abordavam, descreviam ou avaliavam os cuidados desenvolvidos nos serviços substitutivos, representam a grande maioria das temáticas ao longo destes 25 anos.

Em seguida vêm as temáticas sobre a implantação e a capilaridade da rede de serviços substitutivos e as que falam do papel e das possibilidades da saúde mental na Atenção Básica, com 28 artigos cada. Temas mais específicos e de tradicional divisão do campo da saúde mental, como Saúde Mental Infanto-juvenil e problemas relacionados ao álcool e outras drogas, tiveram 28 e 19 trabalhos respectivamente.

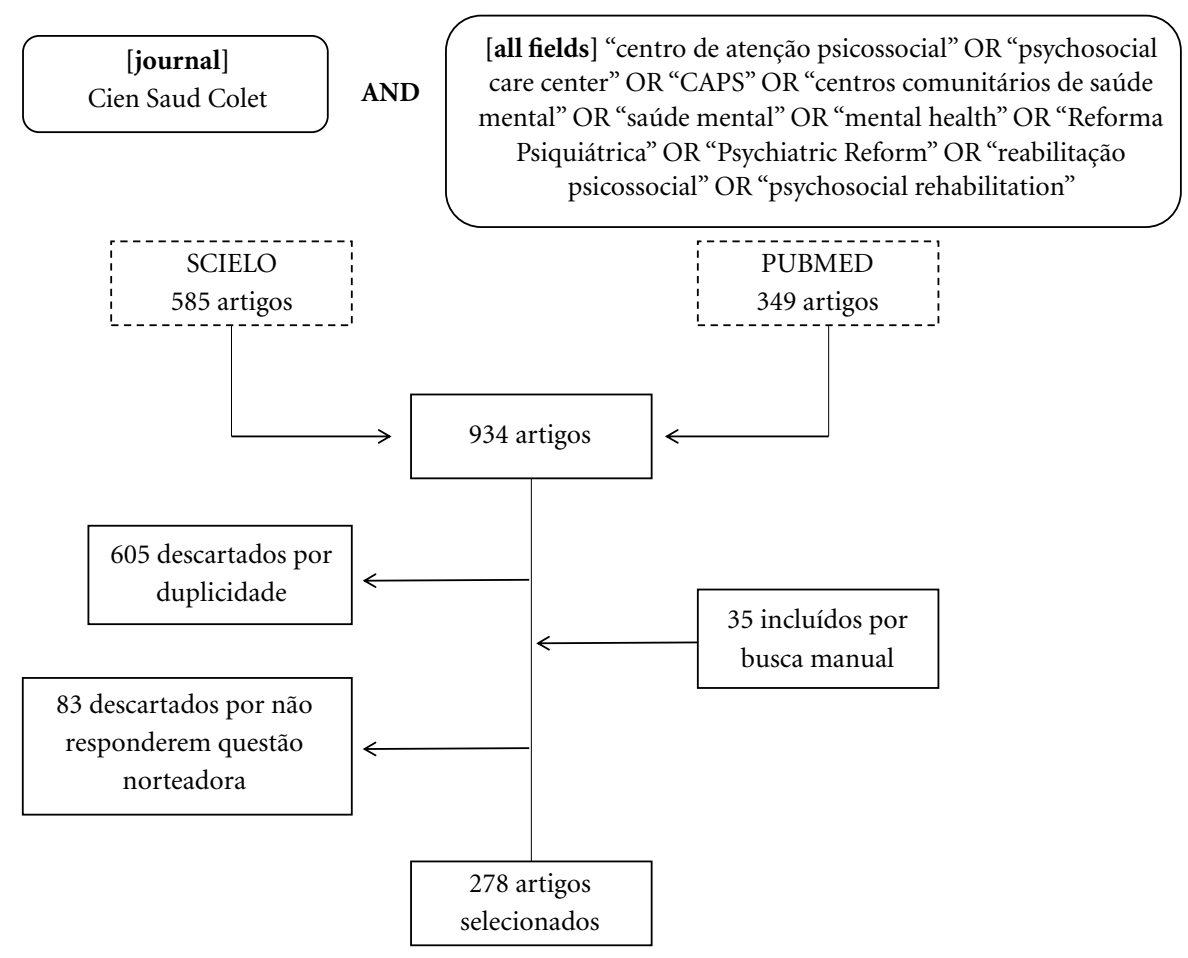

Figura 1. Processo de seleção dos artigos analisados. 


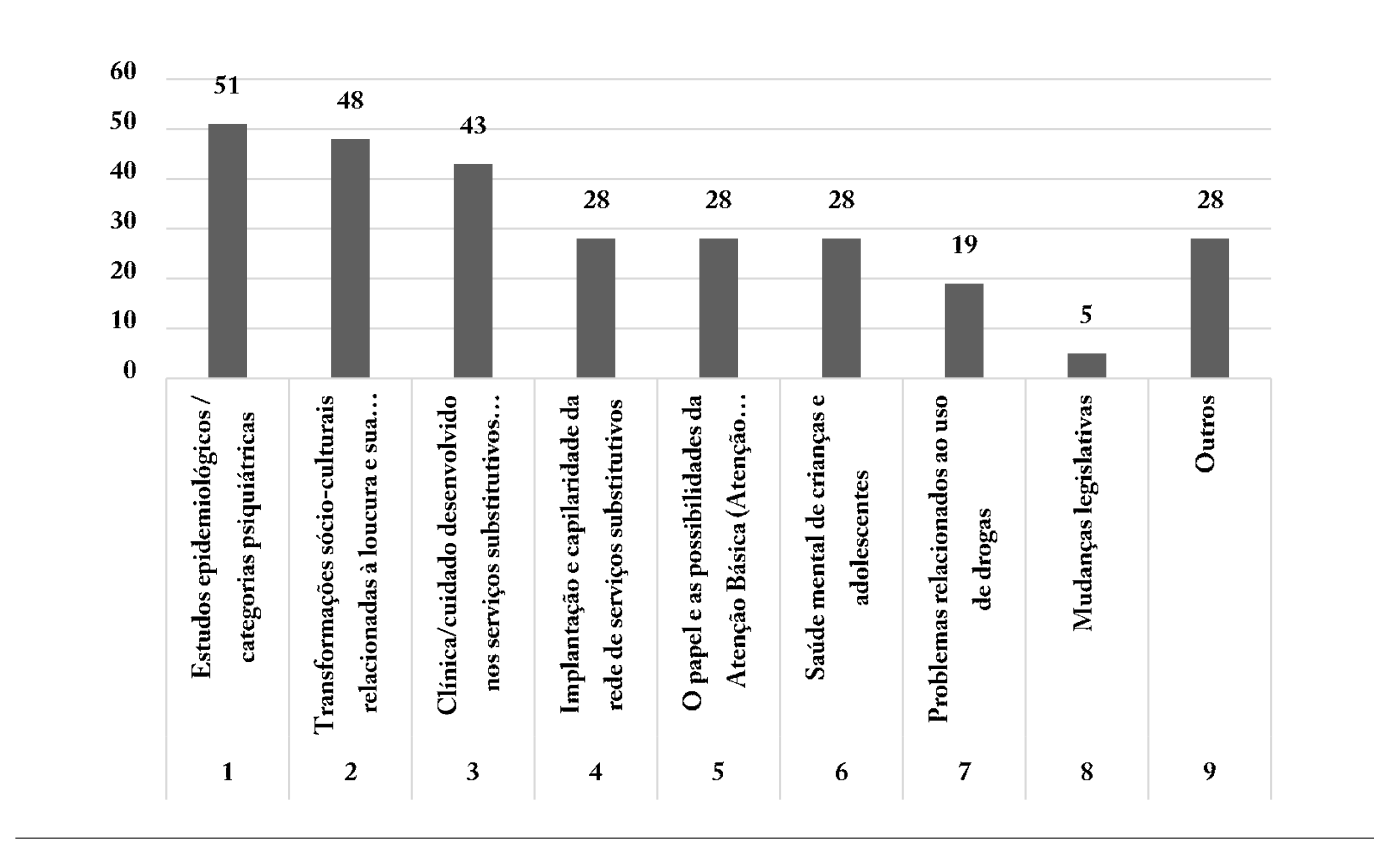

Gráfico 1. Número de artigos publicados por temática específica no campo da saúde mental ( $\mathrm{n}=278$ artigos).

Foram consideradas como "outros" as temáticas relacionadas à: saúde mental no sistema prisional, saúde mental na saúde suplementar, saúde mental dos trabalhadores, estruturação de redes de saúde de outros países, análise de raça e cor sobre a saúde mental, pesquisas no campo da saúde mental, saúde mental da população idosa.

Nos seus 25 anos de existência, o periódico publicou 5.033 artigos e o ano que se destacou como o de maior ocorrência de artigos com o foco em saúde mental foi 2011, com 40 (0,8\% do total), seguido de 2009 e 2013, com 34 (0,7\%) e $31(0,6 \%)$ artigos, respectivamente (Gráfico 2).

A partir de 2009 vemos um crescimento substancial das publicações na revista. Somente nesse ano houve mais publicações do que nos dez anos anteriores. Este crescimento não foi pontual e o ano de 2009 parece demarcar uma mudança do patamar quantitativo de publicações voltadas para a saúde mental. Neste período podemos observar as publicações de Editais de fomento do Ministério da Saúde/CNPq Programa Pesquisas para o SUS (PPSUS) que priorizaram a área da SM nos anos de 2006, 2008 e 2009. O aumento de publicações pode estar relacionado com esse estímulo à produção do conhecimento e, obviamente, à imensa expansão de serviços ocorrida nesses anos, cujas normatizações parecem refletir, da mesma forma, picos nas produções ${ }^{5}$.

O Gráfico 3 foi o resultado do agrupamento dos trabalhos publicados de acordo com o tipo de estudo relatado pelos pesquisadores. A maioria dos trabalhos analisados utiliza metodologias qualitativas. Os 123 estudos qualitativos analisados representam quase $45 \%$ de todos os trabalhos publicados envolvendo a temática da saúde mental.

Os estudos que utilizaram metodologias quantitativas vieram em seguida, em termos de frequência, com 76 (27\%) ao todo. Apenas 9 (3\%) estudos aplicavam tanto metodologias qualitativas como quantitativas. Enquanto que 42 (15\%) eram artigos de revisão e outros 28 (10\%) foram classificados como teóricos ou de opinião.

No Gráfico 4 são analisadas as regiões de origem dos autores dos trabalhos publicados. Muitos trabalhos possuíam mais de um autor e mais de uma instituição envolvida, mas, por outro lado, como foram retirados desta análise os artigos com autores de origem exclusiva internacional, o número total que vemos na tabela é menor que o total de artigos lidos nesta revisão. Portanto, o contabilizado no gráfico é o número de instituições nacionais por região envolvidas na publicação 


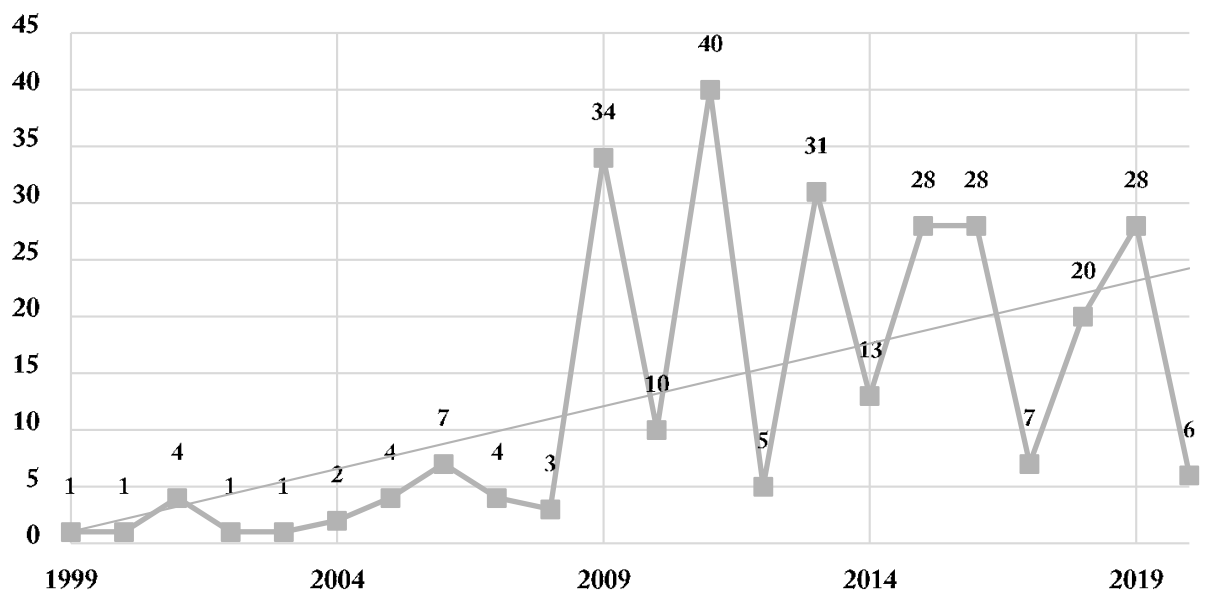

Grafico 2. Número de artigos com temas relacionados à Saúde Mental publicados por ano (n=278 artigos).

*Os seis artigos considerados no ano de 2020 correspondem aos publicados até março.

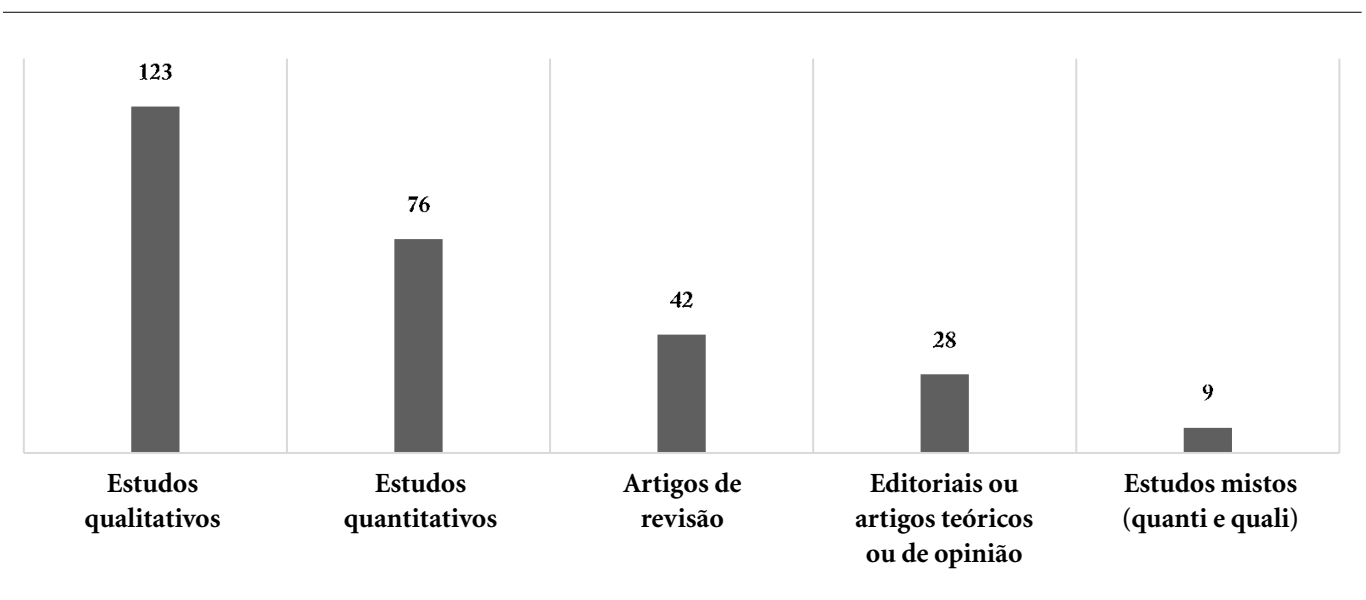

Grafico 3. Número de artigos publicados de acordo com o tipo/modalidade de estudo ( $\mathrm{n}=278$ artigos).

dos artigos avaliados. Assim, autores provenientes de Instituições do Sudeste foram citados 159 vezes nos trabalhos avaliados, significando $58 \%$ das citações. As Instituições do Nordeste vieram em segundo lugar com $20 \%$ das citações, seguida da Região Sul com $18 \%$. As Instituições da Região Centro Oeste foram citadas 3\% das vezes e a Região Norte apenas $1 \%$. Todas as Instituições que constavam como origem dos autores eram públi- cas e sua grande maioria universidades públicas brasileiras. Dos 278 estudos, 28 tinham como autoria pesquisadores de outros países (México, Colômbia, Canadá, Inglaterra, Israel, Espanha, Argentina, Austrália e Portugal), seja sozinhos ou em coautoria com os autores brasileiros.

Cada categoria foi analisada posteriormente com vistas a observar possíveis tendências e mudanças ao longo dos anos. A seguir, discutimos 


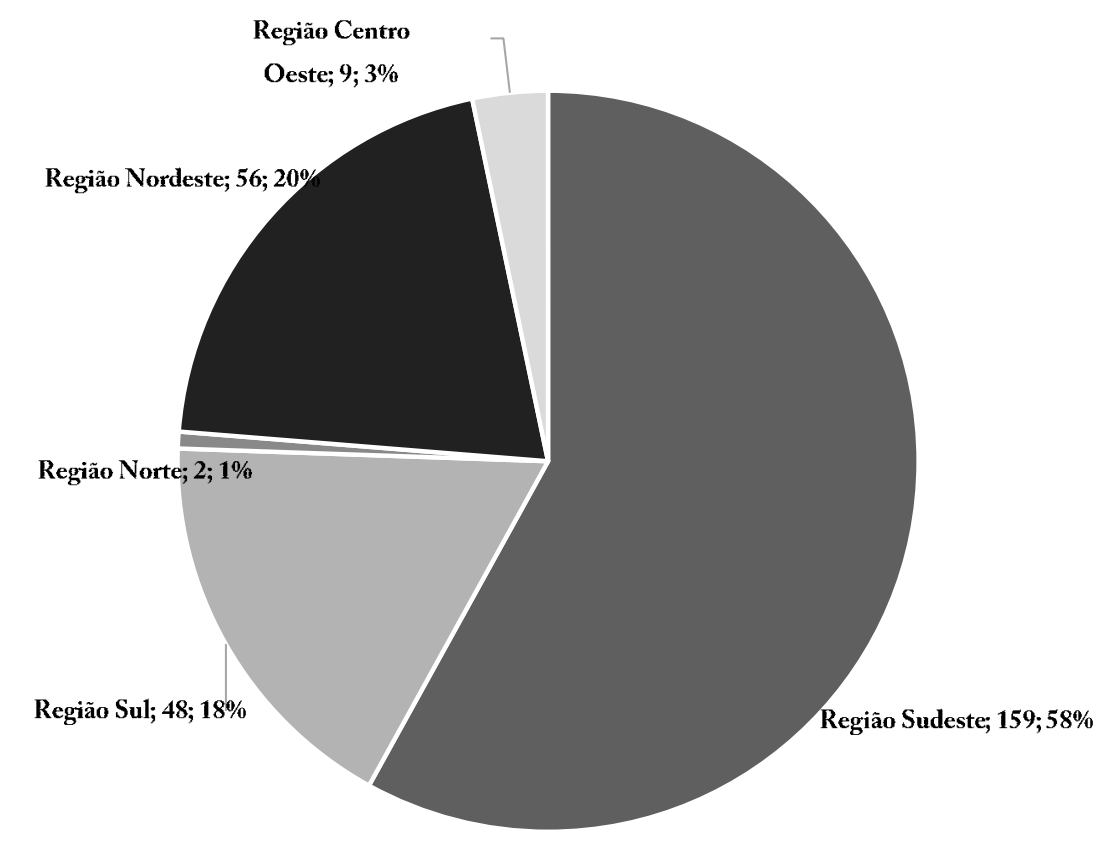

Grafico 4. Número de intituições nacionais envolvidas por artigos publicados de acordo com a origem institucional dos autores (Região Geográfica).

os resultados obtidos a partir de cada uma delas, especificamente.

Transformações socioculturais relacionadas à loucura e sua abordagem

Podemos afirmar que a sanção da chamada Lei de Saúde Mental, marca o começo da produção bibliográfica neste campo. Com início em 2001, as publicações mantêm a média de $2 /$ ano até 2008, com destaque para temática da cidadania ${ }^{7,8}$, do movimento social e militância em $\mathrm{SM}^{9,10}$, mudanças no cuidado e prática clínica ${ }^{11,12}$, saúde do trabalhador de $\mathrm{SM}^{13,14}$, representações na mídia ${ }^{15} \mathrm{e}$ transformações no ensino ${ }^{16}$. No ano de 2009, os artigos trataram da Reforma Psiquiátrica trazendo contrapontos entre o modelo manicomial e as concepções biológicas da saúde mental. Temas como cidadania, redes de suporte social e cuidado territorial foram discutidos, enfatizando-se a importância da implementação de serviços substitutivos e a implantação da legislação para redirecionar o modelo de atenção ${ }^{17-20}$. A participação social aparece como tema correlato à construção de políticas de saúde, apontando-se a necessidade de se superar desafios relacionados à representatividade, legitimidade e participação ${ }^{21}$. O período 2011-2013 concentra a metade das publicações desta categoria (22 artigos), com destaque para a participação de usuários no desenvolvimento de pesquisas em $\mathrm{SM}^{22-24} \mathrm{e}$ nas políticas e práticas ${ }^{25,26}$. A estratégia da Gestão Autônoma da Medicação (GAM) e do recovery fazem-se presentes ${ }^{27}$. De 2014 a 2019, os estudos refletiram sobre os avanços no modelo assistencial e na sociedade com relação ao tema da SM, apontando importantes retrocessos nas políticas públicas da área nos últimos anos. É destacada a necessidade de se ampliar os estudos sobre relações familiares, condições de moradia e renda, direito à saúde e trabalho ${ }^{28,29}$.

\section{Mudanças legislativas}

A primeiras publicações referentes a essa categoria são de 2009 e abordam os avanços na implantação de políticas de SM e a participação social como estratégia para construção da refor$\mathrm{ma}^{30}$, assim como a necessidade de avançar a Lei $\mathrm{n}^{\circ} 10.216$ em consonância com os princípios e as diretrizes do SUS ${ }^{31}$. A interface entre SM e justiça, no âmbito do judiciário e da atenção às pessoas 
em conflito com a lei, é abordada em $2014^{32}$ e, em 2016, artigos discutem a redução de danos tomada como paradigma ético, clínico e político, a partir da política de drogas ${ }^{33}$, e apontam uma mudança paulatina de modelos normativos sobre os problemas com drogas, superando a visão psiquiátrica rumo ao modelo psicossocial ${ }^{34}$.

Implantação, capilaridade e funcionamento da rede de serviços substitutivos

De 2001 a 2009, os artigos versam sobre dificuldades na implementação da SM no cotidiano dos serviços e o convívio com práticas características de instituições asilares, resgatando a perspectiva dos trabalhadores sobre a produção das práticas nos serviços ${ }^{35,36}$. Alguns artigos avaliaram a rede de SM de regiões e municípios, discutindo municipalização, importância da gestão, capacitação de equipes e participação social ${ }^{37,38}$. Cerca de $40 \%$ dos artigos deste eixo foram publicados em 2011, e entre eles constam discussões sobre satisfação no trabalho em SM e suas relações com questões internas e externas aos serviços ${ }^{39}$, o papel da psiquiatria na reforma psiquiátrica ${ }^{40}$, a importância da infraestrutura e da equipe nos CAPS $^{41}$, particularidades do funcionamento da rede a partir de uma organização não governamental ${ }^{42}$ e a importância da articulação entre entes federativos. Outros $40 \%$ estão compreendidos entre 2013 e 2019. Diversos pontos são discutidos nesse período, como: sofrimento moral dos trabalhadores ${ }^{43}$, consolidação de uma rede de serviços especializados no SUS para autistas ${ }^{44}$ e baixa coordenação estadual dos CAPS, produzindo discrepâncias de cobertura e de funcionamento entre os diferentes municípios ${ }^{45}$.

Estão presentes pesquisas avaliativas, sobre acesso aos serviços para problemas com drogas ${ }^{46}$ e RAPS locais ${ }^{47}$, indicando que as avaliações dos serviços de SM devem estender-se para além da comparação com o modelo hospitalocêntrico ${ }^{48}$, sendo constatada uma centralidade do CAPS ad na rede de atenção aos usuários de drogas. A partir de uma perspectiva histórica, Almeida e Campos $^{49}$ abordaram a relação entre as mudanças políticas municipais, a constituição do SUS e a atenção às questões de saúde mental, com ênfase nos movimentos sociais, de trabalhadores, usuários e familiares. Os trabalhos são críticos à estruturação do processo de trabalho na rede de atenção psicossocial. O referencial teórico foi o da reforma psiquiátrica brasileira e a defesa pelos cuidados em liberdade, em que os pesquisadores refletiram criticamente sobre como essa rede estava sendo construída. É recorrente o reconhecimento da potência da rede substitutiva e da ampliação do acesso que dela adveio. Entretanto, as dificuldades apontadas são de base estrutural, como insuficiência de recursos humanos e/ ou falta de capacitação profissional. Enquanto os CAPS são vistos como grande avanço, as pesquisas também acrescentaram novos desafios: estigma, preconceito e tutela continuam presentes e práticas manicomiais persistem nos serviços substitutivos $^{50-55}$.

Clínica/cuidado desenvolvido nos serviços substitutivos (CAPS e RAPS)

Apontam-se consensos: mudança de uma visão psiquiátrica para um modelo psicossocial, precisando ainda de maior amplitude das ações quando comparada a outros países. A falta de estrutura da RAPS e os bons resultados do apoio matricial como modelo de integração entre CAPS e UBS são aspectos centrais em grande parte desses estudos. A prevalência de sofrimento psíquico nas equipes e nos familiares também foram pontos abordados. Publicação de 2006 aponta dificuldades na implementação da clínica dos serviços substitutivos. O convívio com práticas asilares e novos tipos de cronicidade foram foco de alguns estudos ${ }^{56-58}$. Nos anos posteriores são abordadas estratégias de cuidado ${ }^{59}$ e o enfoque sob a dimensão de gênero ${ }^{42,60-63}$. Mais da metade das publicações relativas a esse eixo ocorreu entre 2011 e 2015. Dentre os conteúdos, observou-se associação entre a crescente ampliação dos CAPS e da atenção psicossocial na Atenção Básica, com diminuição das taxas de internação em alguns períodos e regiões, apontando para a relevância da articulação entre os serviços, as famílias e as comunidades $^{64}$. A falta de consenso entre movimentos sociais, trabalhadores e formuladores foi debatida e propostas para a participação de maior número de atores foram apontadas. A necessidade de construção de aliança entre usuários e profissionais, mas também entre usuários e academia para horizontalização do cuidado, fortalecimento do combate ao estigma, formulação de consensos sobre boas práticas e denúncia à crescente medicalização da vida são algumas reflexões ${ }^{42,62,65-67}$.

A necessidade de suporte social e a relevância dos CAPS para o processo de inclusão foram aspectos reconhecidos na clínica, com destaque à intervenção familiar ${ }^{68,69}$. A ambiguidade apresentada pelas famílias e pelos serviços no suporte vs. tutela, também foi levantada ${ }^{70,71}$.

Alguns artigos abordam o Acompanhamento Terapêutico e o trabalho com grupos nos CAPS. As discussões consideraram o modelo de atenção territorial com vistas à integralidade $\mathrm{e}^{72-74}$. Artigos 
alertaram para a adaptação das ofertas para as singularidades das demandas e das experiências socioculturais dos usuários ${ }^{75-77}$. Salienta-se a necessidade de maior investimento em pesquisa, formulação de políticas e implementação de cuidado à população idosa ${ }^{78}$. A formação de profissionais e as condições para exercer ações qualificadas nos serviços substitutivos também foram abordados $^{79-81}$. A importância das estratégias de apoio aos familiares na RAPS foi apontada, recomendando-se educação permanente ${ }^{82,83}$, sendo reiterada a relevância da avaliação de serviços a partir da satisfação de usuários. $(A B)$

O papel e as possibilidades da Atenção Básica

A primeira publicação se deu em 2001, apontando a lógica biomédica reproduzida por profissionais e familiares e reforçada pela insuficiência do sistema público de SM local ${ }^{84}$. Apenas 8 anos depois voltaram a aparecer publicações. A relação entre CAPS e PSF/ESF foi um tema recorrente nos artigos, discutindo-se integralidade do cuidado, articulação em rede, dificuldades de desenvolvimento da atenção em SM na Atenção Básica, papel do Agente Comunitário de Saúde nos casos de SM e superação do modelo biomé$\operatorname{dico}^{85-90}$.

A SM infantojuvenil na $\mathrm{AB}$ também foi objeto de estudos, evidenciando dificuldades em reconhecer, avaliar, tratar e encaminhar situações ${ }^{91-93}$. A avaliação de prevalência e de padrão de consumo de psicofármacos em unidade PSF revelou a relevância da $\mathrm{AB}$ para melhorar o acesso e o uso racional de medicamentos ${ }^{94}$. O Apoio Matricial foi considerado importante para a implementação e a qualificação do cuidado psicossocial ${ }^{95-102}$. No biênio 2015-6 os estudos reconhecem a potencialidade da Atenção Primária para o acompanhamento de SM, favorecida pelo vínculo com a população. Contudo, observam a persistência de práticas de cuidado coletivas e singularizadas concomitantemente à manutenção da lógica biomédica $^{103-105}$. Conexões entre clínica, contexto social e cultural para as intervenções de SM na $\mathrm{AB}$ foram apontadas ${ }^{106}$. De 2018 a 2020, as redes de apoio são prevalentes como tema, apontandose a prevenção e o acompanhamento de pessoas com Transtornos Mentais Comuns ${ }^{107}$, o suporte para os usuários da $\mathrm{SM}^{108}$, a função do NASF junto às $\mathrm{UBS}^{98} \mathrm{e}$ o Apoio Matricial ${ }^{109}$.

Problemas relacionados ao uso de drogas

O número de artigos desta temática (19) é pequeno em comparação ao total (278), correspondendo a $6,8 \%$. As publicações são esparsas, sendo publicados de 1 a 3 artigos sobre o tema por ano, com períodos sem nenhuma publicação. Não foi percebido aumento das publicações relacionado ao investimento do governo federal no programa "Crack, é possível vencer" ${ }^{110}$. Vários estudos têm uma visão estigmatizante dessa população, mantendo um enfoque psiquiátrico. A perspectiva da Redução de Danos, consolidada como estratégia no cenário internacional, tímida nas iniciativas do governo nacional, foi tema de apenas um artigo $^{111}$, que destaca a garantia dos direitos humanos e a inclusão social dos usuários de drogas, ao passo que houve avanço na atenção dos policy makers. Vários trabalhos apontam dificuldades de mensuração de resultados, abrangência e eficácia da Redução de Danos, sugerindo investimento em avaliações. Um estudo retoma o processo histórico da Política de Álcool e Outras Drogas no Brasil, tendo em vista os atravessamentos políticos, sociais e clínicos, apontando a necessidade de financiamento e acompanhamento das ações ${ }^{112}$. Outros estudos também consideraram as ações preventivas pontuais e descontinuadas $^{113-117}$. Problemas relacionados a diversas substâncias psicoativas foram analisados: uso abusivo de álcool ${ }^{118}$, tabaco e medicamentos psi$\operatorname{cotrópicos}^{113}$, maconha ${ }^{119}$ e drogas injetáveis ${ }^{120}$. Evidenciou-se a importância da detecção precoce e de sua associação com fatores sociodemográficos para direcionar as estratégias de prevenção ${ }^{121}$. Mudanças na abordagem dos profissionais, maior adesão às metodologias interativas e fomento da intersetorialidade entre saúde e educação também foram salientadas ${ }^{122,123}$.

$S M$ de crianças e adolescentes

A partir de 2010 cresce o número de publicações sobre a SM de crianças e adolescentes. O tema é abordado a partir de um leque diversificado de aspectos, sendo mais numerosos aqueles relacionados à violência sofrida pelo público infantojuvenil ${ }^{53,124-129}$; caracterização de jovens em conflito com a lei e as condições das instituições de medidas socioeducativas (MSE) ${ }^{112,130-132}$; políticas de SM e tipo de tratamento oferecido pelos serviços substitutivos ${ }^{33,133-137}$. Entre os anos 2000-2010 destacam-se estudos que ressaltam a necessidade de prevenção de suicídio. Também é salientada a importância de investimento na formação de professores ${ }^{127}$. A violência volta a ser discutida entre 2011-2015, destacando-se discussões de fatores no desenvolvimento e na SM, a necessidade de atenção para a SM das mães, conflitos familiares e precariedade socioeconômica $^{128,138,139}$. Outro aspecto reiterado foi a SM de jovens em conflito com a lei, reconhecendo a precariedade das instituições responsáveis, de- 
nunciando a manutenção da lógica manicomial nas instituições de $\mathrm{MSE}^{130}$; e a alta prevalência de transtornos mentais nesse público ${ }^{112}$. Identificase, ainda, um estudo sobre o bullying ${ }^{140}$ e outro sobre a construção de rede de cuidados territorial ${ }^{133}$. Tszesnioski et al. ${ }^{133}$ identificaram que as crianças possuíam vínculos mais fortes com agentes comunitários de saúde e profissionais de creche do que com os serviços de SM. É no período entre 2016-2020 que encontramos maior número de estudos sobre as políticas de SM voltadas para crianças e adolescentes, apontando avanços, mas também reforçando a necessidade de maiores investimentos em termos de efetividade dos serviços e de acesso a informações e cuidados $^{134-137}$.

Artigo aborda crianças que sofrem violência sexual ${ }^{129}$; outro associa violência, bullying e uso de substâncias psicoativas entre adolescentes ${ }^{53}$. Os jovens em conflito com a lei voltam a ser abordados, apontando-se baixa oferta de tratamento em CAPSad e CAPSi ${ }^{131}$; e as demandas de SM desse público ${ }^{132}$. Outro tema foi o modo como crianças e adolescentes experimentam as crises psicossociais, destacando-se a necessidade de que os CAPSi ofereçam espaços de elaboração ${ }^{141}$. Há também levantamento das condições sociais e emocionais de mães, a baixa escolaridade influenciando as dificuldades na constituição do vínculo com o bebê $\hat{e}^{121}$. E, finalmente, um artigo aborda os Transtornos do Espectro Autista e as limitações dos serviços do SUS para lidar com essa demanda ${ }^{135}$.

Estudos epidemiológicos/categorias psiquiátricas

Grande parte dos estudos são descritivos, medem prevalências de transtorno mental, embora cada um deles trabalhe com públicos específicos ou em contextos singulares. Outra parte apresenta pesquisas quantitativas sobre diferentes condições de saúde, índices de violência, qualidade de vida, oferta e uso de serviços de saúde e traçam relações de associação simples. Foram mais numerosas as pesquisas sobre prevalência de transtorno mental em idosos ${ }^{142-147}$; em profissionais de saúde $^{148-151}$; e em pessoas institucionalizadas ${ }^{152-154}$, publicações que crescem a partir de 2009. Alguns abordaram a exposição de crianças a situações de violência ${ }^{155,156}$. Prevalência de transtornos psiquiátricos em profissionais de saúde da $\mathrm{AB}^{148}$; e condições de saúde bucal em moradores de Serviços Residenciais Terapêuticos ${ }^{157}$. As temáticas se repetem entre 2011 e 2015, tais como a SM de profissionais de saúde ${ }^{149-151}$ ou a prevalência de transtornos mentais em pessoas institucionalizadas $^{153,158}$. A gama de temas é bastante diversa, sendo a originalidade e a abrangência de muitos estudos baixa. Essa categoria cresce quantitativamente a partir de 2016, podendo apontar certa facilidade relativa dos estudos quantitativos para serem publicados na Revista.

Outros

Trata-se de um grupo com temas bastante diversificados que apontam para a necessidade de maiores investimentos em pesquisa, como é o caso das relações entre SM e questões étnico-raciais e de gênero ${ }^{60}$; e da relação entre condições de vida nas favelas e $\mathrm{SM}^{159}$. Dois temas que se repetiram, indicando que a comunidade acadêmica já reconhece sua importância. A investigação científica em SM começa a ser tematizada, na análise do investimento do Ministério da Saúde em pesquisa e desenvolvimento ${ }^{160}$. Houve também artigo sobre a construção de indicadores avaliativos de políticas de atenção à saúde da pessoa idosa vítima de acidentes e violência ${ }^{161}$. Dois artigos trataram da questão da SM do trabalhador ${ }^{162,163}$. Em 2011 há um conjunto de artigos que analisa a Reforma Psiquiátrica nos contextos mundial ${ }^{164}$ e brasileiro, as políticas de SM brasileiras e seu processo de implementação, os entraves, os desafios e as conquistas que lhe foram inerentes ${ }^{165-171}$.

São publicadas também discussões acerca de metodologia de pesquisa em $\mathrm{SM}^{172}$, indo do uso de narrativas ${ }^{173}$ à relação entre pesquisa e clíni$\mathrm{ca}^{174}$; da adoção de técnicas de entrevistas coerentes com o ideário da Reforma Psiquiátrica ${ }^{175}$ até abordagens etnográficas ${ }^{176}$. Destaca-se ainda, artigo que versa sobre a participação de usuários de SM no ensino de psicopatologia ${ }^{24}$. Há artigos que abordam o trabalho em SM no contexto de desastres socioambientais ${ }^{177,178}$; bem como trabalhos sobre determinantes sociais da SM em favelas ${ }^{159}$; a oferta de serviços de SM pela saúde suplemen$\operatorname{tar}^{179}$; religiosidade e $\mathrm{SM}^{180}$; sistema penal e $\mathrm{SM}^{32}$; vigilância da saúde do trabalhador e $\mathrm{SM}^{181}$; e representação social do terapeuta comunitário no SUS ${ }^{182}$. Entre 2016 e 2020, o trabalho de SM em contextos de desastres volta a ser discutido ${ }^{183}$. Artigos abordam a SM e a depressão na população idosa $^{184,185}$, enquanto outros discutem questões raciais $^{186}$, mobilidade social e transtornos mentais em adultos ${ }^{187}$ e intervenções de SM em migrantes expostos à violência em seus países de origem ${ }^{188}$.

\section{Discussão}

Podemos afirmar que o estabelecimento da política pública de saúde mental, bem como o acompanhamento dos serviços que compõem 
a RAPS, em particular, incluídos os entraves da assistência comunitária frente à determinação de fatores como estigma e discriminação têm sido tema crescente nos últimos anos, notadamente desde 2009, o que aponta para a área de SM como profícua no campo da Saúde Coletiva. Os editais de pesquisa e a forte expansão de serviços, vivida desde 2003, podem ter repercutido na ampliação dessas publicações. Alguns temas despontam como preocupações mais contemporâneas (raça, gênero) e, surpreendentemente, outros parecem não ter acompanhado a crescente indução das políticas públicas, ao menos no âmbito da saúde coletiva, como o tema do cuidado às pessoas com problemas com drogas, ainda que não tenham sido incluídos termos específicos nas buscas. O leve aumento de estudos quantitativos em anos recentes pode estar refletindo certo viés de seleção da Revista, cabendo a pergunta se esses estudos têm aumentado em quantidade ou se tem sido mais fácil para eles atravessar a cada vez mais exigente barreira da avaliação por pares, em um ambiente cada vez mais competitivo como tem sido o das publicações de Saúde Coletiva no Brasil. Com relação às temáticas priorizadas por entidades internacionais como a OMS, as publicações da Revista Ciência \& Saúde Coletiva parecem ainda atreladas ao cenário brasileiro e latino-americano. Temáticas como o gap de mortalidade, e estudos de implementação e avaliações de ampla escala persistem ausentes das publicações. Por outro lado, temáticas que poderiam ser autóctones e de interesse para o cenário mundial, como as relações entre desigualdade social e barreiras à assistência; SM em situações de violência; relações entre SM, saúde indígena e ecologia, por exemplo, encontram-se totalmente ausentes nas publicações estudadas.

\section{Colaboradores}

RO Campos, DVD Santos, AV Diaz, B Emerich, T Trape, CAP Gama, CEM Amaral, RE Poderoso, AL Ferrer, L Miranda, MB Pereira e LT Surjus participaram igualmente de todas as fases do estudo: desenho, revisão, análise de resultados e revisão da versão final.

\section{Conclusões}

O período estudado permite acompanhar o nascimento e o desenvolvimento de um campo de estudo que se apoia nas mudanças trazidas pela constituição de 1988. A fundação do Sistema Único de Saúde, e todo seu aparato conceitual e legislativo, permitiu processos de transformação. Nosso estudo permite acompanhar o processo de transição paradigmática do campo de saber Saúde Mental e Coletiva no Brasil. Pudemos identificar a característica multidisciplinar e intersetorial do campo, envolvendo diversas disciplinas para refletir sobre o mesmo objeto, desconstruindo certa visão psiquiátrica da doença mental, influenciando mudanças na legislação, nas instituições e na sociedade. É interessante perceber que, num primeiro momento, os textos apontam as potencialidades do campo a partir da redemocratização, como se um leque temático e metodológico fosse se abrindo ao longo dos anos, indicando a complexidade da tarefa. Em seguida, à medida que novos serviços e práticas foram sendo desenvolvidos, a produção teórica passa a dialogar com esta nova realidade, refletindo tanto as dificuldades como os inegáveis avanços conquistados. É interessante perceber que nesse processo a voz do usuário foi ganhando maior relevância, evidenciando que a estruturação do campo da Saúde Mental e Coletiva no Brasil está intimamente relacionada ao social, à cidadania, ao enfrentamento das desigualdades, dos preconceitos e - em última instância - às questões políticas e da democracia. 


\section{Agradecimentos}

Agradecemos aos editores o convite para realizar esta revisão, que nos permitiu voltar a trabalhar juntos, em alguns casos após vários anos. Todos os autores (exceto a bibliotecária Rosana Evangelista Poderoso) foram membros do Grupo de Pesquisa Saúde Coletiva e Saúde Mental: Interfaces realizando seus doutorados sob orientação da Prof. Rosana Onocko Campos e encontramse hoje nucleados em diversas Universidades do país.

\section{Referências}

1. Cook JA, Razzano LA, Swarbrick MA, Jonikas JA, Yost C, Burke L, Steigman PJ, Santos A. Health risks and changes in self-efficacy following community health screening of adults with serious mental illnesses. PLoS ONE 2015 [acessado 2020 Abr 10]; 13(10):4. Disponível em: https://www.ncbi.nlm.nih.gov/pmc/articles/ PMC4395322/

2. World Health Organization (WHO). Mental Health Gap Action Programme. MhGAP intervention guide for mental, neurological and substance use disorders in non-specialized health settings: version 1.0. Geneva: WHO; 2010. [acessado 2020 Abr 10]. Disponível em: https://apps.who.int/iris/handle/10665/44406

3. Thornicroft GTM. What are the arguments for community-based mental health care? Health Evidence Network report. Copenhagen: WHO Regional Office for Europe; 2003. [acessado 2020 Abr 10]. Disponível em: http://www.euro.who.int/document/E82976.pdf

4. MLF. Reaffirming democracy and the universal right to healthcare in times of ultraneoliberalism. Cien Saude Colet 2018 [acessado 2020 Abr 10]; 23(6):17171718. Disponível em: https://www.scielo.br/pdf/csc/ v23n6/1413-8123-csc-23-06-1717.pdf

5. Brasil. Ministério da Saúde (MS). Saúde mental no SUS: cuidado em liberdade, defesa de direitos e rede de atenção psicossocial, relatório de gestão 2011-2015. Brasília: MS. [acessado 2020 Abr 10]. Disponível em: https://portalarquivos.saude.gov.br/images/pdf/2016/ junho/27/Relat--rio-Gest--o-2011-2015---.pdf

6. Onocko-Campos RT. Mental health in Brazil: strides, setbacks, and challenges. Cad Saude Publica 2019 [acessado 2020 Abr 10]; 35(11):e00156119. Disponível em: https://www.scielo.br/scielo.php?pi$\mathrm{d}=$ S0102-311X2019001300501\&script=sci_artteXt\&tlng=en

7. Torre EHG,Amarante P. Protagonismo e subjetividade: a construção coletiva no campo da saúde mental. Cien Saude Colet 2001 [acessado 2020 Abr 10]; 6(1):73-85. Disponível em: http://www.scielo.br/scielo.php?scrip$\mathrm{t}=\mathrm{sci}$ arttext\&pid=S1413-81232001000100006\& $=\mathrm{pt}$

8. Medeiros SMD, Guimarães J. Cidadania e saúde mental no Brasil: contribuição ao debate. Cien Saude Colet 2002 [acessado 2020 Abr 10]; 7(3):571-579. Disponível em: http://www. scielosp.org/scielo.php?script=sci_arttext\&pi$\mathrm{d}=$ S1413-81232002000300014\& $=\mathrm{pt}$

9. Ramos S. O papel das ONGs na construção de políticas de saúde: a Aids, a saúde da mulher e a saúde mental. Cien Saude Colet 2004 [acessado 2020 Abr 10]; 9(4):1067-1078. Disponível em: http:// www.scielo.br/scielo.php?script=sci_arttext\&pi$\mathrm{d}=$ S1413-81232004000400027\& $=\mathrm{pt}$

10. Lüchmann LHH, Rodrigues J. O movimento antimanicomial no Brasil. Cien Saude Colet 2007 [acessado 2020 Abr 10]; 12(2):399-307. Disponível em: http:// www.scielo.br/scielo.php?script=sci_arttext\&pi$\mathrm{d}=$ S1413-81232007000200016\&lng $=\mathrm{pt}$

11. Onocko-Campos R. O encontro trabalhador-usuário na atenção à saúde: uma contribuição da narrativa psicanalítica ao tema do sujeito na saúde coletiva. Cien Saude Colet 2005 [acessado 2020 Abr 10]; 10(3):573-583. Disponível em: http:// www.scielo.br/scielo.php?script $=$ sci_arttext\&pi$\mathrm{d}=$ S1413-81232005000300015\&lng=pt. > 
12. Guimarães J, Saeki T. Sobre o tempo da loucura em Nise da Silveira. Cien Saude Colet 2007 [acessado 2020 Abr 10]; 12(2):531-538. Disponível em: http:// www.scielo.br/scielo.php?script=sci_arttext\&pi$\mathrm{d}=$ S1413-81232007000200029\&lng=pt

13. Araújo TMD, Graça CC, Araújo E. Estresse ocupacional e saúde: contribuições do Modelo Demanda-Controle. Cien Saude Colet 2003 [acessado 2020 Abr 10]; 8(4):991-1003. Disponível em: http:// www.scielosp.org/scielo.php?script=sci_arttext\&pi$\mathrm{d}=$ S1413-81232003000400021\& $=\mathrm{pt}$

14. Sato L, Bernardo MH. Saúde mental e trabalho: os problemas que persistem. Cien Saude Colet 2005 [acessado 2020 Abr 10]; 10(4):869-878. Disponível em: http://www.scielo.br/scielo.php?script=sci_arttext\&pid=S1413-81232005000400011\&=pt

15. Machado AL. Reforma psiquiátrica e mídia: representações sociais na Folha de S. Paulo. Cien Saude Colet 2004 [acessado 2020 Abr 10]; 9(2):483-491. Disponível em: http://www.scielo.br/scielo.php?script=sci_arttext\&pid=S1413-81232004000200024\&=pt

16. Guimarães J, Medeiros SMD. Contribuição ao ensino de saúde mental sob o signo da desinstitucionalização. Cien Saude Colet 2001 [acessado 2020 Abr 10]; 6(1):97-104. Disponível em: http:// www.scielo.br/scielo.php?script=sci_arttext\&pi$\mathrm{d}=$ S1413-81232001000100008\& $=\mathrm{pt}$

17. Silva MBBE. Reforma, responsabilidades e redes: sobre o cuidado em saúde mental. Cien Saude Colet 2009 [acessado 2020 Abr 10]; 14(1):149-158. Disponível em: http://www.scielosp.org/scielo.php?scrip$\mathrm{t}=$ sci_arttext\&pid=S1413-81232009000100020\&=pt

18. Hirdes A. A reforma psiquiátrica no Brasil: uma (re) visão. Cien Saude Colet 2009 [acessado 2020 Abr 10]; 14(1):297-305. Disponível em: http://www.scielosp.org/scielo.php?script $=$ sci_arttext $\&$ pid $=$ S1413 $-81232009000100036 \&=\mathrm{pt}$

19. Hirdes A. Autonomia e cidadania na reabilitação psicossocial: uma reflexão. Cien Saude Colet 2009 [acessado 2020 Abr 10]; 14(1):165-171. Disponível em: http://www.scielosp.org/scielo.php?script=sci_arttext\&pid=S1413-81232009000100022\&=pt

20. Menezes M, Yasui S. O psiquiatra na atenção psicossocial: entre o luto e a liberdade. Cien Saude Colet 2009 [acessado 2020 Abr 10]; 14(1):217-226. Disponível em: http://www.scielosp.org/scielo.php?script=sci_ arttext\&pid=S1413-81232009000100027\& $=\mathrm{pt}$

21. Guimarães JMX, Jorge MSB, Maia RCF, Oliveira LC, Morais APP, Lima MPO, Assis MMA, Santos AM. Participação social na saúde mental: espaço de construção de cidadania, formulação de políticas e tomada de decisão. Cien Saude Colet 2010 [acessado 2020 Abr 10]; 15(4):2113-2122. Disponível em: http:// www.scielo.br/scielo.php?script=sci_arttext\&pi$\mathrm{d}=\mathrm{S} 1413-81232010000400025 \&=\mathrm{pt}$

22. Passos E, Otanari TMC, Emerich BF, Guerini L. O Comitê Cidadão como estratégia cogestiva em uma pesquisa participativa no campo da saúde mental. Cien Saude Colet 2013 [acessado 2020 Abr 10]; 18(10):2919-2928. Disponível em: http:// www.scielo.br/scielo.php?script=sci_arttext\&pi$\mathrm{d}=$ S1413-81232013001000016\& $=\mathrm{pt}$
23. Presotto RF, Silveira M, Delgado PGG, Vasconcelos EM. Experiências brasileiras sobre participação de usuários e familiares na pesquisa em saúde mental. Cien Saude Colet 2013 [acessado 2020 Abr 10]; 18(10):2837-2845. Disponível em: http:// www.scielo.br/scielo.php?script=sci_arttext\&pi$\mathrm{d}=$ S1413-81232013001000008\& $=\mathrm{pt}$

24. Leal EM, Serpa Junior ODD. Acesso à experiência em primeira pessoa na pesquisa em Saúde Mental. Cien Saude Colet 2013 [acessado 2020 Abr 10]; 18(10):2939-2948. Disponível em: http:// www.scielo.br/scielo.php?script=sci_arttext\&pi$\mathrm{d}=$ S1413-81232013001000018\& $=\mathrm{pt}$

25. Campos GWDS, Onocko-Campos RT, Del Barrio LR. Políticas e práticas em saúde mental: as evidências em questão. Cien Saude Colet [acessado 2020 Abr 10]; 18(10):2797-2805. Disponível em: http:// www.scielo.br/scielo.php?script=sci_arttext\&pi$\mathrm{d}=$ S1413-81232013001000002\& $=\mathrm{pt}$

26. Bosi MLM, Carvalho LB, Ximenes VM, Melo AKS, Godoy MGC. Inovação em saúde mental sob a ótica de usuários de um movimento comunitário no nordeste do Brasil. Cien Saude Colet 2012 [acessado 2020 Abr 10]; 17(3):643-651. Disponível em: http:// www.scielosp.org/scielo.php?script=sci_arttext\&pi$\mathrm{d}=\mathrm{S} 1413-81232012000300010 \&=\mathrm{pt}$

27. Barrio LRD, Cyr C, Benisty L, Richard P. Gaining Autonomy \& Medication Management (GAM):new perspectives on well-being, quality of life and psychiatric medication. Cien Saude Colet 2013 [acessado 2020 Abr 10]; 18(10):2879-2887. Disponível em: http://www.scielo.br/scielo.php?script=sci_arttex$\mathrm{t} \& \mathrm{pid}=\mathrm{S} 1413-81232013001000012 \&=\mathrm{pt}$

28. Amarante P, Nunes MDO. A reforma psiquiátrica no SUS e a luta por uma sociedade sem manicômios. Cien Saude Colet 2018 [acessado 2020 Abr 10]; 23(6):2067-2074. Disponível em: http:// www.scielo.br/scielo.php?script=sci_arttext\&pi$\mathrm{d}=$ S1413-81232018000602067\& $=\mathrm{pt}$

29. Arruda AE, Modesto AL, Dias Júnior CS. Trajetória em narrativas: loucuras e a cidade de Belo Horizonte, Brasil. Cien Saude Colet 2018 [acessado 2020 Abr 10]; 23(4):1201-1210. Disponível em: http:// www.scielo.br/scielo.php?script=sci_arttext\&pi$\mathrm{d}=$ S1413-81232018000401201\& $=\mathrm{pt}$

30. Oliveira AGBD, Conciani ME. Participação social e reforma psiquiátrica: um estudo de caso. Cien Saude Colet 2009 [acessado 2020 Abr 10]; 14(1):319-31. Disponível em: http://www.scielosp.org/scielo.php?scrip$\mathrm{t}=\mathrm{sci}$ _arttext\&pid=S1413-81232009000100038\& $=\mathrm{pt}$

31. Cavalcante FG, Goldson E. Avanços na implantação de políticas e ações no campo da deficiência e da saúde mental. Cien Saude Colet 2009 [acessado 2020 Abr 10]; 14(1):4. Disponível em: http:// www.scielosp.org/scielo.php?script=sci_arttext\&pi$\mathrm{d}=$ S1413-81232009000100001\& $=\mathrm{pt}$

32. Silva EQ, Brandi CQACS. "Essa medida de segurança é infinita ou tem prazo de vencimento?": interlocuções e desafios entre o direito e a psicologia no contexto judiciário. Cien Saude Colet 2014 [acessado 2020 Abr 10]; 19(9):3947-3954. Disponível em: http:// www.scielo.br/scielo.php?script=sci_arttext\&pi$\mathrm{d}=$ S1413-81232014000903947\& $=\mathrm{pt}$ 
33. Teixeira MB, Ramôa ML, Engstrom E, Ribeiro JM Tensões paradigmáticas nas políticas públicas sobre drogas: análise da legislação brasileira no período de 2000 a 2016. Cien Saude Colet 2017 [acessado 2020 Abr 10]; 22(5):1455-1466. Disponível em: http:// www.scielo.br/scielo.php?script=sci_arttext\&pi$\mathrm{d}=$ S1413-81232017002501455\& $=\mathrm{pt}$

34. Mendes RO, Pacheco PG, Nunes JPCOV, Crespo PS, Cruz MS. Revisão da literatura sobre implicações para assistência de usuários de drogas da descriminalização em Portugal e Brasil. Cien Saude Colet 2019 [acessado 2020 Abr 06]; 24(9):3395-3406. Disponível em: http://www.scielo.br/scielo.php?script=sci_arttext\&pid=S1413-81232019000903395\&lng=pt. Epub 09-Set-2019. https://doi.org/10.1590/141381232018249.27472017.

35. Campos CMS, Soares CB. A produção de serviços de saúde mental: a concepção de trabalhadores. Cien Saude Colet 2003 [acessado 2020 Abr 06]; 8(2):621-628. Disponível em: http://www.scielo.br/scielo.php?scrip$\mathrm{t}=\mathrm{sci}$ arttext\&pid=S1413-81232003000200022\& $\mathrm{\alpha}=\mathrm{pt}$

36. Oliveira AGBD, Alessi NP. Cidadania: instrumento e finalidade do processo de trabalho na reforma psiquiátrica. Cien Saude Colet 2005 [acessado 2020 Abr 06]; 10(1):191-203. Disponível em: http:// www.scielo.br/scielo.php?script=sci_arttext\&pi$\mathrm{d}=$ S1413-81232005000100026\& $=\mathrm{pt}$

37. Consoli GL, Hirdes A, Costa JSDD. Saúde mental nos municípios do Alto Uruguai, RS, Brasil: um diagnóstico da reforma psiquiátrica. Cien Saude Colet 2009, [acessado 2020 Abr 06]; 14(1):117-128. Disponível em: http://www.scielosp.org/scielo.php?script=sci_ arttext\&pid $=S 1413-81232009000100017 \&=\mathrm{pt}$

38. Luzio CA, Abbate S. A atenção em Saúde Mental em municípios de pequeno e médio portes: ressonâncias da reforma psiquiátrica. Cien Saude Colet 2009 [acessado 2020 Abr 06]; 14(1):105-116. Disponível em: http://www.scielosp.org/scielo.php?script=sci_arttex$\mathrm{t} \& \mathrm{pid}=\mathrm{S} 1413-81232009000100016 \&=\mathrm{pt}$

39. Guimarães JMX, Jorge MSB, Assis MMA. (In)satisfação com o trabalho em saúde mental: um estudo em Centros de Atenção Psicossocial. Cien Saude Colet 2011 [acessado 2020 Abr 06]; 16(4):2145-2154. Disponível em: http://www.scielo.br/scielo.php?script=sci_arttext\&pid=S1413-81232011000400014\&=pt

40. Serpa Junior ODD. O papel da psiquiatria na reforma psiquiátrica. Cien Saude Colet 2011 [acessado 2020 Abr 06]; 16(12):4675-4684 Disponível em: http:// www.scielo.br/scielo.php?script=sci_arttext\&pi$\mathrm{d}=$ S1413-81232011001300016\& $=\mathrm{pt}$

41. Kantorski LP, Coimbra VCC, Silva ENF, Guedes AC, Cortes JM, Santos F. Avaliação qualitativa de ambiência num Centro de Atenção Psicossocial. Cien Saude Colet 2011 [acessado 2020 Abr 06]; 16(4):2059-2066. Disponível em: http://www.scielo.br/scielo.php?scrip$\mathrm{t}=\mathrm{sci}$ arttext\&pid=S1413-81232011000400005\& $=\mathrm{pt}$

42. Queiroz MDS, Delamuta LA. Saúde mental e trabalho interdisciplinar: a experiência do "Cândido Ferreira" em Campinas. Cien Saude Colet 2011 [acessado 2020 Abr 06]; 16(8):3603-3612. Disponível em: http:// www.scielo.br/scielo.php?script=sci_arttext\&pi$\mathrm{d}=\mathrm{S} 1413-81232011000900028 \&=\mathrm{pt}$
43. Oliveira CA, Oliveira DCP, Cardoso EM, Aragão ES, Bittencourt MN. Sofrimento moral de profissionais de enfermagem em um Centro de Atenção Psicossocial. Cien Saude Colet 2020 [acessado 2020 Abr 06];25(1):191-198. Disponível em: https://www.scielo.br/pdf/csc/v25n1/1413-8123-csc-25-01-0191.pdf

44. Rios C, Camargo Júnior KR. Especialismo, especificidade e identidade - as controvérsias em torno do autismo no SUS. Cien Saude Colet 2019 [acessado 2020 Abr 06]; 24(3):1111-1120. Disponível em: https:// www.scielosp.org/article/csc/2019.v24n3/1111-1120/

45. Costa NR, Corrêa SGP, Silva PRF. Considerações sobre a acessibilidade nos Centros de Atenção Psicossocial no Brasil. Cien Saude Colet 2015 [acessado 2020 Abr 06]; 20(10):3139-3150. Disponível em: http:// www.scielosp.org/scielo.php?script=sci_arttext\&pi$\mathrm{d}=\mathrm{S} 1413-81232015001003139 \&=\mathrm{pt}$

46. Ribeiro JM, Moreiro MR, Bastoa FI, Inglez-Dias A, Fernandes FMB. Acesso aos serviços de atenção em álcool, crack e outras drogas: o caso do município do Rio de Janeiro, Brasil. Cien Saude Colet 2016 [acessado 2020 Abr 06]; 21(1):71-81. Disponível em: http:// www.scielo.br/scielo.php?script=sci_arttext\&pi$\mathrm{d}=$ S1413-81232016000100071\& $=\mathrm{pt}$

47. Fagundes Júnior HM, Desviat M, Silva PRF. Reforma psiquiátrica no Rio de Janeiro: situação atual e perspectivas futuras. Cien Saude Colet 2016 [acessado 2020 Abr 06]; 21(5):1449-60. Disponível em: http:// www.scielo.br/scielo.php?script=sci_arttext\&pi$\mathrm{d}=$ S1413-81232016000501449\& $=\mathrm{pt}$

48. Costa PHA, Colugnati FAB, Ronzani TM. Avaliação de serviços em saúde mental no Brasil: revisão sistemática da literatura. Cien Saude Colet 2015 [acessado 2020 Abr 06]; 20(10):3243-3253. Disponível em: http://www.scielo.br/scielo.php?script=sci_arttext\&pid $=$ S1413-81232015001003243\& $=$ pt

49. Almeida IS, Campos GWS. Análise sobre a constituição de uma rede de Saúde Mental em uma cidade de grande porte. Cien Saude Colet 2019 [acessado 2020 Abr 06]; 24(7):2715-26. Disponível em: http:// www.scielosp.org/scielo.php?script=sci_arttext\&pi$\mathrm{d}=$ S1413-81232019000702715\& $=\mathrm{pt}$

50. Wetzel C, Kantorski LP, Olschowsky A, Schneider JF, Camatta MW. Dimensões do objeto de trabalho em um Centro de Atenção Psicossocial. Cien Saude Colet 2011 [acessado 2020 Abr 06]; 16(4):2133-2143. Disponível em: http://www.scielo.br/scielo.php?script=sci_arttext\&pid=S1413-81232011000400013\&=pt

51. Oliveira RFD, Andrade LOMD, Goya N. Acesso e integralidade: a compreensão dos usuários de uma rede de saúde mental. Cien Saude Colet 2012 [acessado 2020 Abr 06]; 17(11):3069-3078. Disponível em: http://www.scielo.br/scielo.php?script=sci_arttext\&pid $=$ S1413-81232012001100023\& $=\mathrm{pt}$

52. Fiorati RC, Saeki T. The prevalence of medical/clinical technology over psychosocial care actions in outpatient mental health services. Cien Saude Colet 2013 [acessado 2020 Abr 06]; 18(10):2957-2963. Disponível em: http://www.scielo.br/scielo.php?script=sci_ arttext\&pid $=$ S1413-81232013001000020\& $=$ pt 
53. Horta CL, Horta RL, Mester A, Weber JLA, Levandowski DC, Lisboa CSM. Bullying e uso de substâncias psicoativas na adolescência: uma revisão sistemática. Cien Saude Colet 2018 [acessado 2020 Abr 06]; 23(1):123-140. Disponível em: https://www.scielo.br/ $\mathrm{pdf} / \mathrm{csc} / \mathrm{v} 23 \mathrm{n} 1 / 1413-8123$-csc-23-01-0123.pdf

54. Pinho ES, Souza ACS, Esperidião E. Processos de trabalho dos profissionais dos Centros de Atenção Psicossocial: revisão integrativa. Cien Saude Colet 2018 [acessado 2020 Abr 06]; 23(1):141-152. Disponível em: http://www.scielo.br/scielo.php?script=sci_arttext\&pid=S1413-81232018000100141\&=pt

55. Dias MK, Ferigato SH, Fernandes ADS. A. Atenção à Crise em saúde mental: centralização e descentralização das práticas. Cien Saude Colet 2020 [acessado 2020 Abr 06]; 25(2):595-602. Disponível em: http:// www.scielosp.org/scielo.php?script=sci_arttext\&pi$\mathrm{d}=\mathrm{S} 1413-81232020000200595 \&=\mathrm{pt}$

56. Cardoso C, Seminotti N. O grupo psicoterapêutico no Caps. Cien Saude Colet 2006 [acessado 2020 Abr 06]; 11(3):775-783. Disponível em: http:// www.scielosp.org/scielo.php?script=sci_arttext\&pi$\mathrm{d}=$ S1413-81232006000300025\& $=\mathrm{pt}$

57. Furtado JP. Avaliação da situação atual dos Serviços Residenciais Terapêuticos no SUS. Cien Saude Colet 2006 [acessado 2020 Abr 06]; 11(3):785-795. Disponível em: http://www.scielosp.org/scielo.php?scrip$\mathrm{t}=$ sci_arttext\&pid=S1413-81232006000300026\&=pt

58. Garcia MLP, Jorge MSB. Vivência de trabalhadores de um centro de atenção psicossocial: estudo à luz do pensamento de Martin Heidegger e HansGeorg Gadamer. Cien Saude Colet 2006 [acessado 2020 Abr 06]; 11(3):765-774. Disponível em: http:// www.scielosp.org/scielo.php?script=sci_arttext\&pi$\mathrm{d}=$ S1413-81232006000300024\& $=\mathrm{pt}$

59. Estellita-Lins C, Oliveira VM, Coutinho MF. Clínica ampliada em saúde mental: cuidar e suposição de saber no acompanhamento terapêutico. Cien Saude Colet 2009 [acessado 2020 Abr 06]; 14(1):195-204. Disponível em: http://www.scielosp.org/scielo.php?script=sci_arttext\&pid=S1413-81232009000100026\& $=$ pt

60. Santos AMCC. Articular saúde mental e relações de gênero: dar voz aos sujeitos silenciados. Cien Saude Colet 2009 [acessado 2020 Abr 06]; 14(4):1177-1182. Disponível em: http://www.scielo.br/scielo.php?scrip$\mathrm{t}=\mathrm{sci}$ arttext\&pid=S1413-81232009000400023\&=pt

61. Batista E, Silva MB. From patient to clinical case: An ethnography with psychiatric inpatient care releases. Cien Saude Colet 2015 [acessado 2020 Abr 06]; 20(2):353-362. Disponível em: http:// www.scielo.br/scielo.php?script $=$ sci_arttext\&pi$\mathrm{d}=$ S1413-81232015000902857\&=pt

62. Jorge MSB. Pinto DM, Quinderé PHD, Pinto AGA, Sousa FSP, Cavalcante CM. Promoção da saúde mental: tecnologias do cuidado: vínculo, acolhimento, co-responsabilização e autonomia. Cien Saude Colet 2011 [acessado 2020 Abr 06]; 16(7):3051-60. Disponível em: http://www.scielo.br/scielo.php?script=sci_arttext\&pid=S1413-8123201 $1000800005 \&=$ pt

63. Rodrigues RC, Marinho TPC, Amorim P. Reforma psiquiátrica e inclusão social pelo trabalho. Cien Saude Colet 2010 [acessado 2020 Abr 06]; 15(Supl. 1):1615-1625. Disponível em: http:// www.scielo.br/scielo.php?script=sci_arttext\&pi$\mathrm{d}=$ S1413-81232010000700073\&=pt
64. Cavalcante AC, Silva RM. Experiências psíquicas de mulheres frequentadoras da rede pública de saúde em Teresina (PI, Brasil). Cien Saude Colet 2011 [acessado 2020 Abr 06]; 16(4):2211-2220. Disponível em: http://www.scielo.br/scielo.php?script=sci_arttext\&pid $=$ S1413-81232011000400020\& $=$ pt

65. Bezerra Júnior B. É preciso repensar o horizonte da reforma psiquiátrica. Cien Saude Colet 2011 [acessado 2020 Abr 06]; 16(12):4598-4600. Disponível em: http://www.scielo.br/scielo.php?script=sci_arttext\&pid=S1413-81232011001300007\&=pt

66. Campos RO, Baccari IP. A intersubjetividade no cuidado à saúde mental: narrativas de técnicos e auxiliares de enfermagem de um Centro de Atenção Psicossocial. Cien Saude Colet 2011 [acessado 2020 Abr 06]; 16(4):2051-2058. Disponível em: http:// www.scielo.br/scielo.php?script=sci_arttext\&pi$\mathrm{d}=$ S1413-81232011000400004\& $=\mathrm{pt}$

67. Silva MBBE. De paciente a causo: uma etnografia com egressos de internação psiquiátrica. Cien Saude Colet 2015 [acessado 2020 Abr 06]; 20(2):353-362. Disponível em: http://www.scielo.br/scielo.php?script=sci_arttext\&pid=S1413-81232015000200353\& $=$ pt

68. Cavalcanti MT, Carvalho MCA, Valência E, Dahl CM, Souza FM. Adaptação da "Critical Time Intervention" para o contexto brasileiro e sua implementação junto a usuários dos centros de atenção psicossocial do município do Rio de Janeiro. Cien Saude Colet 2011 [acessado 2020 Abr 06]; 16(12):4635-4642. Disponível em: http://www.scielo.br/scielo.php?script=sci_ arttext $\&$ pid $=$ S1413-81232011001300012\& $=$ pt

69. Salles MM, Barros S. Inclusão social de pessoas com transtornos mentais: a construção de redes sociais na vida cotidiana. Cien Saude Colet 2013 [acessado 2020 Abr 06]; 18(7):2129-2138. Disponível em: http:// www.scielo.br/scielo.php?script=sci_arttext\&pi$\mathrm{d}=\mathrm{S} 1413-81232013000700028 \&=\mathrm{pt}$

70. Dias MK. A experiência social da psicose no contexto de um Centro de Atenção Psicossocial. Cien Saude Colet 2011 [acessado 2020 Abr 06]; 16(4):2155-2164. Disponível em: http://www.scielo.br/scielo.php?scrip$\mathrm{t}=$ sci_arttext\&pid=S1413-81232011000400015\&=pt

71. Muramoto MT, Mângia EF. A sustentabilidade da vida cotidiana: um estudo das redes sociais de usuários de serviço de saúde mental no município de Santo André (SP, Brasil). Cien Saude Colet 2011 [acessado 2020 Abr 06]; 16(4):2165-2177. Disponível em: http:// www.scielo.br/scielo.php?script=sci_arttext\&pi$\mathrm{d}=\mathrm{S} 1413-81232011000400016 \&=\mathrm{pt}$

72. Lemos PM, Cavalcante Júnior FS. Psicologia de orientação positiva: uma proposta de intervenção no trabalho com grupos em saúde mental. Cien Saude Colet 2009; 14(1):233-242. Disponível em: http:// www.scielosp.org/scielo.php?script=sci_arttext\&pi$\mathrm{d}=$ S1413-81232009000100029\& $=\mathrm{pt}$

73. Amorim AKDMA, Dimenstein M. Desinstitucionalização em saúde mental e práticas de cuidado no contexto do serviço residencial terapêutico. Cien Saude Colet 2009 [acessado 2020 Abr 06]; 14(1):195-204. Disponível em: http://www.scielosp.org/scielo.php?scrip$\mathrm{t}=\mathrm{sci}$ _arttext\&pid=S1413-81232009000100025\&=pt

74. Iglesias A, Avellar LZ. Apoio Matricial: um estudo bibliográfico. Cien Saude Colet 2014 [acessado 2020 Abr 06]; 19(9):3791-3798. Disponível em: http:// www.scielo.br/scielo.php?script=sci_arttext\&pi$\mathrm{d}=$ S1413-81232014000903791\& $\mathrm{pt}$ 
75. Constantinidis TC, Andrade AND. Demanda oferta no encontro entre profissionais de saúde mental e familiares de pessoas com sofrimento psíquico. Cien Saude Colet 2015 [acessado 2020 Abr 06]; 20(2):333-342. Disponível em: http://www. scielosp.org/scielo.php?script=sci_arttext\&pi$\mathrm{d}=$ S1413-81232015000200333\& $=\mathrm{pt}$

76. Jardim VMDR. Kantorski LP, Oliveira MM, Treichel CAS, Rodrigues CGSS, Dias LV. Limitações de comportamento social entre usuários da Rede de Atenção Psicossocial no sul do Brasil. Cien Saude Colet 2015 [acessado 2020 Abr 06]; 20(5):1371-1378. Disponível em: http://www.scielo.br/scielo.php?script=sci_arttext\&pid $=$ S1413-81232015000501371\&=pt

77. Barbosa JAG, Souza MCMR, Freitas MIDF. A abordagem da sexualidade como aspecto essencial da atenção integral de pessoas com transtornos mentais. Cien Saude Colet 2015 [acessado 2020 Abr 06]; 20(7):2165-2172. Disponível em: http://www. scielosp.org/scielo.php?script $=$ sci_arttext\&pi$\mathrm{d}=$ S1413-81232015000702165\& $=\mathrm{pt}$

78. Conte M, Cruz, CW, Silva CG, Castilhos NRM, Nicolella ADR. Encontros ou esencontros: histórias de idosos que tentaram suicídio e a Rede de Atenção Integral em Porto Alegre/RS, Brasil. Cien Saude Colet 2015 [acessado 2020 Abr 06]; 20(6):1741-1749. Disponível em: http://www.scielo.br/scielo.php?script=sci_arttext\&pid=S1413-81232015000601741\&=pt

79. Muylaert CJ, Rolim Neto ML, Zioni F, Reis AOA. Vivências de trabalhadores de Centros de Atenção Psicossocial Infantojuvenil: organização social de saúde e prefeitura. Cien Saude Colet 2015 [acessado 2020 Abr 06]; 20(11):3467-3476. Disponível em: http:// www.scielo.br/scielo.php?script=sci_arttext\&pi$\mathrm{d}=$ S1413-81232015001103467\& $=\mathrm{pt}$

80. Zanella CG, Aguiar PM, Storpirtis S. Atuação do farmacêutico na dispensação de medicamentos em Centros de Atenção Psicossocial Adulto no município de São Paulo, SP, Brasil. Cien Saude Colet 2015 [acessado 2020 Abr 06]; 20(2):325-332. Disponível em: http:// www.scielo.br/scielo.php?script=sci_arttext\&pi$\mathrm{d}=$ S1413-81232015000200325\& $=\mathrm{pt}$

81. Silva SN, Lima MG. Assistência Farmacêutica na Saúde Mental: um diagnóstico dos Centros de Atenção Psicossocial. Cien Saude Colet 2017 [acessado 2020 Abr 06]; 22(6):2025-36. Disponível em: http:// www.scielo.br/scielo.php?script=sci_arttext\&pi$\mathrm{d}=$ S1413-81232017002602025\&=pt

82. Eloia SC, Oliveira EM, Lopes MVO, Parente JRF, Eloia SMC, Lima DS. Sobrecarga de cuidadores familiares de pessoas com transtornos mentais: análise dos serviços de saúde. Cien Saude Colet 2018 [acessado 2020 Abr 06]; 23(9):3001-3011. Disponível em: http:// www.scielo.br/scielo.php?script=sci_arttext\&pi$\mathrm{d}=\mathrm{S} 1413-81232018000903001 \&=\mathrm{pt}$

83. Silva SN, Lima MG, Ruas CM. Avaliação de serviços de saúde mental brasileiros: satisfação dos usuários e fatores associados. Cien Saude Colet 2018 [acessado 2020 Abr 06]; 23(11):3799-3810. Disponível em: http://www.scielo.br/scielo.php?script=sci_arttext\&pid $=$ S1413-81232018001103799\& $=\mathrm{pt}$
84. Brêda MZ, Augusto LGDS. O cuidado ao portador de transtorno psíquico na atenção básica de saúde. Cien Saude Colet 2001 [acessado 2020 Abr 06]; 6(2):471-480. Disponível em: http://www.scielosp.org/scielo.php?script=sci_arttext \&pid=S1413 $-81232001000200016 \&=p t$

85. Delfini PSDS, Sato MT, Antoneli PP, Guimarães POS Parceria entre CAPS e PSF: o desafio da construção de um novo saber. Cien Saude Colet 2009 [acessado 2020 Abr 06]; 14(Supl. 1):1483-1492. Disponível em: $\mathrm{http}: / /$ www.scielo.br/scielo.php?script=sci_arttext\&pid $=$ S1413-81232009000800021\& $=\mathrm{pt}$

86. Figueiredo MD, Campos RO. Saúde Mental na atenção básica à saúde de Campinas, SP: uma rede ou um emaranhado? Cien Saude Colet 2009 [acessado 2020 Abr 06]; 14(1):129-138. Disponível em: http:// www.scielosp.org/scielo.php?script=sci_arttext\&pi$\mathrm{d}=$ S1413-81232009000100018\& $=\mathrm{pt}$

87. Jucá VJDS, Nunes MDO, Barreto SG. Programa de Saúde da Família e Saúde Mental: impasses e desafios na construção da rede. Cien Saude Colet 2009 [acessado 2020 Abr 06]; 14(1):173-182. Disponível em: http://www.scielosp.org/scielo.php?script=sci_arttex$\mathrm{t} \& \mathrm{pid}=\mathrm{S} 1413-81232009000100023 \&=\mathrm{pt}$

88. Silveira DPD, Vieira ALS. Saúde mental e atenção básica em saúde: análise de uma experiência no nível local. Cien Saude Colet 2009 [acessado 2020 Abr 06]; 14(1):139-148. Disponível em: http://www. scielosp.org/scielo.php?script=sci_arttext\&pi$\mathrm{d}=$ S1413-81232009000100019\& $=\mathrm{pt}$

89. Vecchia MD, Martins STF. Concepções dos cuidados em saúde mental por uma equipe de saúde da família, em perspectiva histórico-cultural. Cien Saude Colet 2009 [acessado 2020 Abr 06]; 14(1):183-193. Disponível em: http://www.scielosp.org/scielo.php?scrip$\mathrm{t}=$ sci_arttext\&pid=S1413-81232009000100024\&=pt

90. Barros MMM, Chagas MIO, Dias MSA. Saberes e práticas do agente comunitário de saúde no universo do transtorno mental. Cien Saude Colet 2009 [acessado 2020 Abr 06]; 14(1):227-232. Disponível em: http:// www.scielo.br/scielo.php?script $=$ sci_arttext\&pi$\mathrm{d}=$ S1413-81232009000100028\&lng=pt. https://doi. org/10.1590/S1413-81232009000100028

91. Tanaka OY, Ribeiro EL. Ações de saúde mental na atenção básica: caminho para ampliação da integralidade da atenção. Cien Saude Colet 2009 [acessado 2020 Abr 06]; 14(2):477-486. Disponível em: http:// www.scielo.br/scielo.php?script=sci_arttext\&pi$\mathrm{d}=$ S1413-81232009000200016\& $=\mathrm{pt}$

92. Ximenes LF, Pesce RP. Problemas de saúde mental em crianças: abordagem na atenção básica. Cien Saude Colet 2009 [acessado 2020 Abr 06]; 14(2):671-672. Disponível em: http://www.scielo.br/scielo.php?scrip$\mathrm{t}=$ sci_arttext\&pid $=$ S1413-81232009000200036\& $=\mathrm{pt}$

93. Fatori D, Brentani A, Grisi SJFE, Miguel EC, Graeff-Martins AS. Prevalência de problemas de saúde mental na infância na atenção primária. Cien Saude Colet 2018 [acessado 2020 Abr 06]; 23(9):3013-3020. Disponível em: http://www.scielo.br/scielo.php?scrip$\mathrm{t}=$ sci_arttext\&pid=S1413-81232018000903013\&=pt 
94. Rocha BS, Werlang MC. Psicofármacos na Estratégia Saúde da Família: perfil de utilização, acesso e estratégias para a promoção do uso racional. Cien Saude Colet 2013 [acessado 2020 Abr 06]; 18(11):3291-3300. Disponível em: https:// www.scielo.br/scielo.php?script $=$ sci_arttext\&pi$\mathrm{d}=$ S1413-81232013001100019\&lng $=\mathrm{pt} \& \ln \mathrm{l}=\mathrm{pt}$

95. Hirdes A. A perspectiva dos profissionais da Atenção Primária à Saúde sobre o apoio matricial em saúde mental. Cien Saude Colet 2015 [acessado 2020 Abr 06]; 20(2):371-382. Disponível em: http:// www.scielo.br/scielo.php?script=sci_arttext\&pi$\mathrm{d}=\mathrm{S} 1413-81232015000200371 \&=\mathrm{pt}$

96. Hirdes A, Scarparo HBK. O labirinto e o minotauro: saúde mental na Atenção Primária à Saúde. Cien Saude Colet 2015 [acessado 2020 Abr 06]; 20(2):383-393. Disponível em: http://www.scielo.br/scielo.php?scrip$\mathrm{t}=\mathrm{sci}$ arttext\&pid=S1413-81232015000200383\&=pt

97. Quinderé PHD, Jorge MSB, Nogueira MSL, Costa LFA, Vasconcelos MGF. Acessibilidade e resolubilidade da assistência em saúde mental: a experiência do apoio matricial. Cien Saude Colet 2013 [acessado 2020 Abr 06]; 18(7):2157-2166. Disponível em: http:// www.scielo.br/scielo.php?script=sci_arttext\&pi$\mathrm{d}=$ S1413-81232013000700031\& $=\mathrm{pt}$

98. Tesser CD, Poli Neto P. Atenção especializada ambulatorial no Sistema Único de Saúde: para superar um vazio. Cien Saude Colet 2017 [acessado 2020 Abr 06]; 22(3):941-951. Disponível em: http:// www.scielo.br/scielo.php?script=sci_arttext\&pi$\mathrm{d}=$ S1413-81232017002300941\& $=\mathrm{pt}$

99. Pinto AGA, Jorge MSB, Vasconcelos MGF, Sampaio JJC, Lima GP, Bastos VC, Sampaio HAC. Apoio matricial como dispositivo do cuidado em saúde mental na atenção primária: olhares múltiplos e dispositivos para resolubilidade. Cien Saude Colet 2017 [acessado 2020 Abr 06]; 17(3):653-660. Disponível em: http:// www.scielosp.org/scielo.php?script=sci_arttext\&pi$\mathrm{d}=\mathrm{S} 1413-81232012000300011 \&=\mathrm{pt}$

100. Silveira ER. Práticas que integram a saúde mental à saúde pública: o apoio matricial e a interconsulta. Cien Saude Colet 2012 [acessado 2020 Abr 06]; 17(9):2377-2386. Disponível em: http:// www.scielo.br/scielo.php?script=sci_arttext\&pi$\mathrm{d}=\mathrm{S} 1413-81232012000900018 \&=\mathrm{pt}$

101. Iglesias A, Avellar LZ. Matriciamento em Saúde Mental: práticas e concepções trazidas por equipes de referência, matriciadores e gestores. Cien Saude Colet 2019 [acessado 2020 Abr 06]; 24(4):1247-1254. Disponível em: http://www.scielo.br/scielo.php?script=sci_arttext\&pid=S1413-81232019000401247\& $=$ pt

102. Saraiva SAL, Zepeda J, Liria AF. Componentes do apoio matricial e cuidados colaborativos em saúde mental: uma revisão narrativa. Cien Saude Colet 2020 [acessado 2020 Abr 06]; 25(2):553-565. Disponível em: http://www.scielosp.org/scielo.php?script=sci_ arttext\&pid=S1413-81232020000200553\&=pt

103. Frosi RV, Tesser CD. Práticas assistenciais em saúde mental na atenção primária à saúde: análise a partir de experiências desenvolvidas em Florianópolis, Brasil. Cien Saude Colet 2015 [acessado 2020 Abr 06]; 20(10):3151-3161. Disponível em: http:// www.scielo.br/scielo.php?script=sci_arttext\&pi$\mathrm{d}=$ S1413-81232015001003151\&=pt
104. Gryschek G, Pinto AAM. Saúde Mental: como as equipes de Saúde da Família podem integrar esse cuidado na Atenção Básica? Cien Saude Colet 2015 [acessado 2020 Abr 06]; 20(10):3255-3262. Disponível em: http://www.scielo.br/scielo.php?script=sci_arttext\&pid $=S 1413-81232015001003255 \&=$ pt

105. Fernandes L, Basílio N, Figueira S, Nunes JM. Saúde mental em medicina geral familiar: obstáculos e expectativas percecionados pelos médicos de família. Cien Saude Colet 2017 [acessado 2020 Abr 06]; 22(3):797-805. Disponível em: http:// www.scielo.br/scielo.php?script=sci_arttext\&pi$\mathrm{d}=\mathrm{S} 1413-81232017002300797 \&=\mathrm{pt}$

106. Athié K, Dowrick C, Menezes ALA, Cruz L, Lima AC, Delgado PGG, Favoretto C, Fortes S. Anxious and depressed women's experiences of emotional suffering and help seeking in a Rio de Janeiro favela. Cien Saude Colet 2017 [acessado 2020 Abr 06]; 22(1):75-86. Disponível em: https://www.scielo.br/scielo.php?scrip$\mathrm{t}=$ sci_arttext\&pid=S1413-81232017000 100075\&ln$\mathrm{g}=\mathrm{en} \& \mathrm{nrm}=\mathrm{iso} \& \operatorname{lng}=\mathrm{en}$

107. Aragão EIS, Campos MR, Portugal FB, Gonçalves DA, Mari JJ, Fortes SLCL. Padrões de Apoio Social na Atenção Primária à Saúde: diferenças entre ter doenças físicas ou transtornos mentais. Cien Saude Colet 2018 [acessado 2020 Abr 06]; 23(7):2339-2350. Disponível em: http://www.scielo.br/scielo.php?script=sci_arttext\&pid=S1413-81232018000702339\&=pt

108. Aragão EIS, Portugal FB, Campos MR, Lopes CS, Mari JJ, Fortes SLCL. Distintos padrões de apoio social percebido e sua associação com doenças físicas (hipertensão, diabetes) ou mentais no contexto da atenção primária. Cien Saude Colet 2017 [acessado 2020 Abr 06]; 22(7):2367-2374. Disponível em: http:// www.scielo.br/scielo.php?script=sci_arttext\&pi$\mathrm{d}=$ S1413-81232017002702367\& $\mathrm{qt}$

109. Saraiva SAL, Zepeda J, Liria AF. Componentes do apoio matricial e cuidados colaborativos em saúde mental: uma revisão narrativa. Cien Saude Colet 2020 [acessado 2020 Abr 06]; 25(2):553-65. Disponível em: http://www.scielosp.org/scielo.php?script=sci_arttext\&pid=S1413-81232020000200553\&=pt

110. Andrade TMD. Reflexões sobre políticas de drogas no Brasil. Cien Saude Colet 2020 [acessado 2020 Abr 06]; 16(12):4665-4674. Disponível em: http:// www.scielo.br/scielo.php?script $=$ sci_arttext\&pi$\mathrm{d}=\mathrm{S} 1413-81232011001300015 \&=\mathrm{pt}$

111. Gomes TB, Vecchia MD. Estratégias de redução de danos no uso prejudicial de álcool e outras drogas: revisão de literatura. Cien Saude Colet 2018 [acessado 2020 Abr 06]; 23(7):2327-2338. Disponível em: http://www.scielo.br/scielo.php?script=sci_arttext\&pid=S1413-81232018000702327\&lng=pt. https:// doi.org/10.1590/1413-81232018237.21152016.

112. Andrade RCD, Assumpção Júnior F, Teixeira IA, Fonseca VAS. Prevalência de transtornos psiquiátricos em jovens infratores na cidade do Rio de Janeiro (RJ, Brasil): estudo de gênero e relação com a gravidade do delito. Cien Saude Colet 2011 [acessado 2020 Abr 06]; 16(4):2179-2188. Disponível em: http:// www.scielo.br/scielo.php?script=sci_arttext\&pi$\mathrm{d}=$ S1413-81232011000400017\& $\mathrm{et}$ 
113. Noto AR. Galduroz JCF. O uso de drogas psicotrópicas e a prevenção no Brasil. Cien Saude Colet 1999 [acessado 2020 Abr 06]; 4(1):145-151. Disponível em: http://www.scielo.br/scielo.php?script=sci_arttex$\mathrm{t} \& \mathrm{pid}=\mathrm{S} 1413=81231999000100012-\& \operatorname{lng}=\mathrm{en} \& \mathrm{nrm}-$ iso

114. Oliveira JF, Paiva MS, Valente CLM. Representações sociais de profissionais de saúde sobre o consumo de drogas: um olhar numa perspectiva de gênero. Cien Saude Colet 2011 [acessado 2020 Abr 06]; 11(2):473-481. Disponível em: http:// www.scielo.br/scielo.php?script=sci_arttext\&pi$\mathrm{d}=$ S1413-81232006000200024\&lng=pt

115. Moraes M. Integral healthcare model for treating problems caused by alcohol and other drugs: perceptions of users, their companions and practitioners. Cien Saude Colet 2008 [acessado $2020 \mathrm{Abr}$ 06]; 13(1):121-133. Disponível em: http://www. scielosp.org/scielo.php?script $=$ sci_arttext\&pi$\mathrm{d}=\mathrm{S} 1413-81232008000100017 \&=\mathrm{pt}$

116. Costa PHAD, Mota DCB, Paiva, FS, Ronzani TM. Desatando a trama das redes assistenciais sobre drogas: uma revisão narrativa da literatura. Cien Saude Colet 2015 [acessado 2020 Abr 06]; 20(2):395-406. Disponível em: http://www.scielo.br/scielo.php?script=sci_arttext\&pid=S1413-81232015000200395\& $=$ pt

117. Vargas ADFM, Campos MM. A trajetória das políticas de saúde mental e de álcool e outras drogas no século XX. Cien Saude Colet 2019 [acessado 2020 Abr 06]; 24(3):1041-1050. Disponível em: http:// www.scielo.br/scielo.php?script=sci_arttext\&pi$\mathrm{d}=\mathrm{S} 1413-81232019000301041 \&=\mathrm{pt}$

118. Sousa FSPD, Oliveira EN. Caracterização das internações de dependentes químicos em Unidade de Internação Psiquiátrica do Hospital Geral. Cien Saude Colet 2010 [acessado $2020 \mathrm{Abr}$ 06]; 15(3):671-677. Disponível em: http://www.scielosp.org/scielo.php?script=sci_arttext\&pid $=S 1413-81232010000300009 \&=$ pt

119. Araújo LF, Castanha AR, Barros APR, Castanha CR. Estudo das representações sociais da maconha entre agentes comunitários de saúde. Cien Saude Colet 2008 [acessado 2020 Abr 06]; 11(3):827-836. Disponível em: http://www.scielo.br/scielo.php?script=sci_arttext\&pid $=$ S1413-81232006000300030\&lng $=$ pt. https://doi.org/10.1590/S1413-81232006000300030

120. Malta M, Cavalcanti S, Gliksman L, Adlaf E, Hacker MAVB, Bertoni N, Massard E, Bastos FI. Behavior and major barriers faced by non-injectable drug users with $\mathrm{HBV} / \mathrm{HCV}$ seeking treatment for hepatitis and drug addiction in Rio de Janeiro, Brazil. Cien Saude Colet 2011 [acessado 2020 Abr 06]; 16(12):4777-4786. Disponivel em: http://www.scielo.br/scielo.php?scrip$\mathrm{t}=\mathrm{sci}$ _arttext\&pid=S1413-81232011001300026\& $=\mathrm{pt}$

121. Silva CC, Costa MCO, Carvalho RC, Amaral MTR, Cruz NLA, Silva MR. Iniciação e consumo de substâncias psicoativas entre adolescentes e adultos jovens de Centro de Atenção Psicossocial Antidrogas/ CAPS-AD. Cien Saude Colet 2014 [acessado 2020 Abr 06]; 19(3):737-745. Disponível em: http:// www.scielo.br/scielo.php?script $=$ sci_arttext\&pi$\mathrm{d}=$ S1413-81232014000300737\& $=\mathrm{pt}$
122. Pedroso RT, Hamann EM. Adequações do piloto do programa Unplugged\# Tamojunto para promoção à saúde e prevenção de drogas em escolas brasileiras. Cien Saude Colet 2019 [acessado 2020 Abr 06]; 24(2):371-381. Disponível em: http:// www.scielo.br/scielo.php?script=sci_arttext\&pi$\mathrm{d}=$ S1413-81232019000200371\& $=\mathrm{pt}$

123. Costa MSO, Alves MVQM, Santos CAST, Carvalho RC, Souza KAP, Sousa HL. Experimentação e uso regular de bebidas alcoólicas, cigarros e outras substâncias psicoativas/SPA na adolescência. Cien Saude Colet 2000 [acessado 2020 Abr 06]; 12(5):1143-1154. Disponível em: http://www.scielo.br/scielo.php?script=sci_arttext\&pid=S1413-81232007000500011\&lng=pt. https://doi.org/10.1590/S1413-81232007000500011.

124. Meneghel S, Armani T, Severino R, Garcia AM, Mafioleti B, Fochi E, Rodrigues F, Armani L, Oliveira M, Rodrigues R. Cotidiano violento: oficinas de promoção em saúde mental em Porto Alegre. Cien Saude Colet 2000 [acessado 2020 Abr 06]; 5(1):193-203. Disponível em: http://www.scielo.br/scielo.php?script=sci_arttext\&pid=S1413-81232000000100017\&=pt

125. Abasse MLF, Oliveira RC, Silva TC, Souza ER. Análise epidemiológica da morbimortalidade por suicídio entre adolescentes em Minas Gerais, Brasil. Cien Saude Colet 2000 [acessado 2020 Abr 06]; 14(2):407-416. Disponível em: http://www.scielo.br/scielo.php?script=sci_arttext\&pid=S1413-81232009000200010\&lng=pt

126. Poletto M, Koller SH, Dell'Aglio DD. Eventos estressores em crianças e adolescentes em situação de vulnerabilidade social de Porto Alegre. Cien Saude Colet 2009 [acessado 2020 Abr 06]; 14(2):455-466. Disponível em: http://www.scielo.br/scielo.php?script=sci_arttext\&pid=S1413-81232009000200014\&lng=pt

127. Assis SG, Avanci JQ, Pesce RP, Ximenes LF. Situação de crianças e adolescentes brasileiros em relação à saúde mental e à violência. Cien Saude Colet 2009 [acessado 2020 Abr 06]; 14, (2):349-361. Disponível em: http://www.scielo.br/scielo.php?script=sci_arttext\&pid $=$ S1413-81232009000200002\& $=\mathrm{pt}$

128. Matos MB, Cruz ACN, Dumith SC, Dias NC, Carret RBP, Quevedo LA. Eventos estressores na família e indicativos de problemas de saúde mental em crianças com idade escolar. Cien Saude Colet 2015 [acessado 2020 Abr 06]; 20(7):2157-2163. Disponível em: http:// www.scielo.br/scielo.php?script=sci_arttext\&pi$\mathrm{d}=$ S1413-81232015000702157\& $=\mathrm{pt}$

129. Fontes LFC, Conceição OC, Machado S. Violência sexual na adolescência, perfil da vítima e impactos sobre a saúde mental. Cien Saude Colet 2017 [acessado 2020 Abr 06]; 22(9):2919-2928. Disponível em: http://www.scielo.br/scielo.php?script=sci_arttex$\mathrm{t} \& \mathrm{pid}=\mathrm{S} 1413-81232017002902919 \&=\mathrm{pt}$

130. Vilarins NPG. Adolescents with mental disorders while serving time and being subjected to socio-educative measures. Cien Saude Colet 2014 [acessado 2020 Abr 06]; 19(3):891-898. Disponível em: http:// www.scielo.br/scielo.php?script $=$ sci_arttext\&pi$\mathrm{d}=\mathrm{S} 1413-81232014000300891 \&=\mathrm{pt}$

131. Costa NDR, Silva PRFD. A atenção em saúde mental aos adolescentes em conflito com a lei no Brasil. Cien Saude Colet 2014 [acessado 2020 Abr 06]; 22(5):1467-1478. Disponível em: http:// www.scielo.br/scielo.php?script=sci_arttext\&pi$\mathrm{d}=$ S1413-81232017002501467\& $=\mathrm{pt}$ 
132. Ribeiro DS, Ribeiro FML, Deslandes SF. Discursos sobre as demandas de saúde mental de jovens cumprindo medida de internação no Rio de Janeiro, Brasil. Cien Saude Colet 2019 [acessado 2020 Abr 06]; 24(10):3837-3846. Disponível em: http:// www.scielo.br/scielo.php?script=sci_arttext\&pi$\mathrm{d}=$ S1413-81232019001003837\& $=\mathrm{pt}$

133. Tszesnioski LC, Nóbrega KBG, Lima MLLT, Facundes VLD. Construindo a rede de cuidados em saúde mental infanto juvenil: intervenções no território. Cien Saude Colet 2015 [acessado 2020 Abr 06]; 20(2):363-370. Disponível em: http://www.scielo.br/scielo.php?scrip$\mathrm{t}=$ sci_arttext\&pid=S1413-81232015000200363\&=pt

134. Teixeira MR, Couto MCV, Delgado PGG. Tensões paradigmáticas nas políticas públicas sobre drogas: análise da legislação brasileira no período de 2000 a 2016. Cien Saude Colet 2017 [acessado 2020 Abr 06]; 22(5):1455-1466. Disponível em: http:// www.scielo.br/scielo.php?script=sci_arttext\&pi$\mathrm{d}=$ S1413-81232017002501455\& $=\mathrm{pt}$

135. Rossi LP, Lovisi GM, Abelha L, Gomide M. Caminhos virtuais e autismo: acesso aos serviços de saúde na perspectiva da Análise de Redes Sociais. Cien Saude Colet 2018 [acessado 2020 Abr 06]; 23(10):3319-3326. Disponível em: http://www.scielo.br/scielo.php?scrip$\mathrm{t}=\mathrm{sci}$ arttext\&pid=S1413-81232018001003319\&=pt

136. Schaefer R, Barbiani R, Nora CRD, Viegas K, Leal SMC, Lora PS, Ciconet R, Micheletti VD. Políticas de Saúde de adolescentes e jovens no contexto luso-brasileiro: especificidades e aproximações. Cien Saude Colet 2018 [acessado 2020 Abr 06]; 23(9):2849-2858. Disponível em: http://www.scielo.br/scielo.php?scrip$\mathrm{t}=$ sci_arttext\&pid=S1413-81232018000902849\&=pt

137. Braga CP, Oliveira AFPL. Políticas públicas na atenção à saúde mental de crianças e adolescentes: percurso histórico e caminhos de participação. Cien Saude Colet 2019 [acessado 2020 Abr 06]; 24(2):401-410. Disponível em: http://www.scielo.br/scielo.php?scrip$\mathrm{t}=$ sci_arttext\&pid=S1413-81232019000200401\&=pt

138. Ribeiro DG, Perosa GB, Padovani FHP. Fatores de risco para o desenvolvimento de crianças atendidas em Unidades de Saúde da Família, ao final do primeiro ano de vida. Cien Saude Colet 2014 [acessado 2020 Abr 06]; 19(1):215-226. Disponível em: http:// www.scielo.br/scielo.php?script $=$ sci_arttext\&pi$\mathrm{d}=$ S1413-81232014000100215\&=pt

139. Rozemberg L, Avanci J, Schenker M, Pires T. Resiliência, gênero e família na adolescência. Cien Saude Colet 2014 [acessado 2020 Abr 06]; 19(3):673-684. Disponível em: http://www.scielo.br/scielo.php?scrip$\mathrm{t}=$ sci_arttext\&pid=S1413-81232014000300673\&=pt

140. Pigozi PL, Machado AL. Bullying na adolescência: visão panorâmica no Brasil. Cien Saude Colet 2015 [acessado 2020 Abr 06]; 20(11):3509-3522. Disponível em: http://www.scielo.br/scielo.php?script=sci_ arttext\&pid=S1413-81232015001103509\&=pt

141. Pereira MO, Sá MC, Miranda L. Uma onda que vem e dá um caixote: representações e destinos da crise em adolescentes usuários de um CAPSi. Cien Saude Colet 2017 [acessado 2020 Abr 06]; 22(11)3733-3742. Disponível em: http://www.scielo.br/scielo.php?scrip$\mathrm{t}=$ sci_arttext\&pid=S1413-81232017021103733\&=pt
142. Siqueira GR, Vasconcelos DT, Duarte GC, Arruda IC, Costa JAS, Cardoso RO. Análise da sintomatologia depressiva nos moradores do Abrigo Cristo Redentor através da aplicação da Escala de Depressão Geriátrica (EDG). Cien Saude Colet 2009 [acessado 2020 Abr 06]; 14(1):253-259. Disponível em: http:// www.scielo.br/scielo.php?script=sci_arttext\&pi$\mathrm{d}=$ S1413-81232009000100031\&lng=pt

143. Apratto Júnior PC. A violência doméstica contra idosos nas áreas de abrangência do Programa Saúde da Família de Niterói (RJ, Brasil). Cien Saude Colet 2010 [acessado 2020 Abr 06]; 15(6):2983-2995. Disponível em: http://www.scielo.br/scielo.php?script=sci_arttext\&pid=S1413-81232010000600037\&=pt

144. Valadares FC, Souza ERD. Violência contra a pessoa idosa: análise de aspectos da atenção de saúde mental em cinco capitais brasileiras. Cien Saude Colet 2010 [acessado 2020 Abr 06]; 15(6):2763-2774. Disponível em: http://www.scielo.br/scielo.php?script=sci_arttext\&pid=S1413-81232010000600014\&=pt

145. Hellwig N, Munhoz TN, Tomasi E. Sintomas depressivos em idosos: estudo transversal de base populacional. Cien Saude Colet 2016 [acessado 2020 Abr 06]; 21(11):3575-3584. Disponível em: http:// www.scielo.br/scielo.php?script=sci_arttext\&pi$\mathrm{d}=$ S1413-81232016001103575\& $=\mathrm{pt}$

146. Martins AMEBL, Nascimento JE, Souza JGS, Sá MAB, Feres SBL, Soares BP, Soares BP, Ferreira EF. Associação entre transtornos mentais comuns e condições subjetivas de saúde entre idosos. Cien Saude Colet 2016 [acessado 2020 Abr 06]; 21(11):3387-3398. Disponível em: http://www.scielo.br/scielo.php?script=sci_arttext\&pid=S1413-81232016001103387\&=pt

147. Guimarães LA, Brito TA, Pithon KR, Jesus CS, Souto CS, Souza SJN. Sintomas depressivos e fatores associados em idosos residentes em instituição de longa permanência. Cien Saude Colet 2019 [acessado 2020 Abr 06]; 24(9):3275-3282. Disponível em: http:// www.scielo.br/scielo.php?script $=$ sci_arttext\&pi$\mathrm{d}=$ S1413-81232019000903275\&lng=pt

148. Braga LCD, Carvalho LRD, Binder MCP. Condições de trabalho e transtornos mentais comuns em trabalhadores da rede básica de saúde de Botucatu (SP). Cien Saude Colet 2019 [acessado 2020 Abr 06]; 15(Supl. 1):1585-1596. Disponível em: http:// www.scielo.br/scielo.php?script=sci_arttext\&pi$\mathrm{d}=$ S1413-81232010000700070\& $=\mathrm{pt}$

149. Resende MC, Azevedo EGS, Lourenço LR, Faria LS, Alves NF, Farina NP, Silva NC, Oliveira SL. Saúde mental e ansiedade em agentes comunitários que atuam em saúde da família em Uberlândia (MG, Brasil). Cien Saude Colet 2011 [acessado 2020 Abr 06]; 16(4):2115-2122. Disponível em: http:// www.scielo.br/scielo.php?script=sci_arttext\&pi$\mathrm{d}=$ S1413-81232011000400011\& $=\mathrm{pt}$

150. Farias CA, Lima POC, Ferreira LA, Cruzeiro ALS, Quevedo LA. Sobrecarga em cuidadores de usuários de um centro de atenção psicossocial infanto-juvenil no sul do Brasil. Cien Saude Colet 2014 [acessado 2020 Abr 06]; 19(12):4819-4827. Disponível em: http:// www.scielo.br/scielo.php?script $=$ sci_arttext\&pi$\mathrm{d}=$ S1413-81232014001204819\&=pt 
151. Knuth BS, da Silva RA, Oses JP, Radtke VA, Cocco RA, Jansen K. Mental disorders among health workers in Brazil. Cien Saude Colet 2015 [acessado 2020 Abr 06]; 20(8):2481-2488. Disponível em: http:// www.scielo.br/scielo.php?script=sci_arttext\&pi$\mathrm{d}=\mathrm{S} 1413-81232015000802481 \&=\mathrm{pt}$

152. Paixão C, Matias D, Alencar I, Nunes M, Sales P, Veiga PHA. Análise da prevalência dos transtornos psíquicos na região metropolitana do Recife. Cien Saude Colet 2009 [acessado 2020 Abr 06]; 14(1):261-266. Disponível em: http://www.scielosp.org/scielo.php?scrip$\mathrm{t}=\mathrm{sci}$ arttext\&pid=S1413-81232009000100032\&=pt

153. Melo MCA, Albuquerque SGC, Luz JHS, Quental PTLF, Sampaio AM, Lima AB. Perfil clínico e psicossocial dos moradores em hospitais psiquiátricos no estado do Ceará, Brasil. Cien Saude Colet 2015 [acessado 2020 Abr 06]; 20(2):343-352. Disponível em: http://www.scielo.br/scielo.php?script=sci_arttext\&pid=S1413-81232015000200343\&=pt

154. Lara APM, Volpe FM. Evolução do perfil das internações psiquiátricas pelo Sistema Único de Saúde em Minas Gerais, Brasil, 2001-2013. Cien Saude Colet 2019 [acessado 2020 Abr 06]; 24(2):659-668. Disponível em: http://www.scielo.br/scielo.php?script=sci_arttext\&pid=S1413-81232019000200659\&=pt

155. Avanci J, Assis S, Oliveira R, Pires T. Quando a convivência com a violência aproxima a criança do comportamento depressivo. Cien Saude Colet 2009 [acessado 2020 Abr 06]; 14(2):383-394. Disponível em: http://www.scielo.br/scielo.php?script=sci_arttext\&pid=S1413-81232009000200008\&=pt

156. Duarte CS, Bordin IAS, Green GR, Hoven CW. Measuring child exposure to violence and mental health reactions in epidemiological studies: challenges and current issues. Cien Saude Colet 2009 [acessado 2020 Abr 06]; 14(2):487-496. Disponível em: http:// www.scielo.br/scielo.php?script=sci_arttext\&pi$\mathrm{d}=$ S1413-81232009000200017\& $=\mathrm{pt}$

157. Jamelli SR, Mendonça MC, Diniz MG, Andrade FBM, Melo JF, Ferreira SR, Silva PV. Saúde bucal e percepção sobre o atendimento odontológico em pacientes com transtorno psíquico moradores de residências terapêuticas. Cien Saude Colet 2009 [acessado 2020 Abr 06]; 15(Supl. 1):1795-1800. Disponível em: http:// www.scielo.br/scielo.php?script=sci_arttext\&pi$\mathrm{d}=\mathrm{S} 1413-81232010000700091 \&=\mathrm{pt}$

158. Leite SCC, Caldeira AP. Ofıcinas terapêuticas para a reabilitação psíquica de pacientes institucionalizados em decorrência da hanseníase. Cien Saude Colet 2015 [acessado 2020 Abr 06]; 20(6):1835-1842. Disponível em: http://www.scielo.br/scielo.php?script=sci_arttext\&pid=S1413-81232015000601835\&=pt

159. Guimarães MBL, Lima CM, Savi EA, Cardoso E, Valla VV, Stotz EN, Lacerda A, Santos MS. Os impasses da pobreza absoluta: a experiência da Ouvidoria Coletiva na região da Leopoldina, Rio de Janeiro (RJ, Brasil). Cien Saude Colet 2011 [acessado 2020 Abr 06]; 16(1):291-300. Disponível em: http:// www.scielosp.org/scielo.php?script=sci_arttext\&pi$\mathrm{d}=$ S1413-81232011000100031\& $=\mathrm{pt}$
160. Caetano R, Vianna CMM, Sampaio MMA, Silva RM, Rodrigues RRD. Análise dos investimentos do Ministério da Saúde em pesquisa e desenvolvimento do período 2000-2002: uma linha de base para avaliações futuras a partir da implementação da agenda nacional de prioridades de pesquisa em saúde. Cien Saude Colet 2010 [acessado 2020 Abr 06]; 15(4):2039-2050. Disponível em: http://www.scielo.br/scielo.php?scrip$\mathrm{t}=$ sci_arttext\&pid=S1413-81232010000400018\& $=\mathrm{pt}$

161. Souza ERD, Correia BSC. Construção de indicadores avaliativos de políticas de atenção à saúde da pessoa idosa vítima de acidentes e violência. Cien Saude Colet 2019 [acessado 2020 Abr 06]; 15(6):2753-2762. Disponível em: http://www.scielo.br/scielo.php?script=sci_arttext\&pid=S1413-81232010000600013\&=pt

162. Araújo TMD, Graça CC, Araújo E. Estresse ocupacional e saúde: contribuições do Modelo Demanda-Controle. Cien Saude Colet 2003 [acessado 2020 Abr 06]; 8(4):991-1003. Disponível em: http:// www.scielosp.org/scielo.php?script=sci_arttext\&pi$\mathrm{d}=\mathrm{S} 1413-81232003000400021 \&=\mathrm{pt}$

163. Sato L, Bernardo MH. Saúde mental e trabalho: os problemas que persistem. Cien Saude Colet 2005 [acessado 2020 Abr 06]; 10(4):869-878. Disponível em: http://www.scielo.br/scielo.php?script=sci_arttext\&pid=S1413-81232005000400011\&=pt

164. Desviat M. Panorama internacional de la reforma psiquiátrica. Cien Saude Colet 2011 [acessado 2020 Abr 06]; 16(12)4615-4622. Disponível em: http:// www.scielo.br/scielo.php?script=sci_arttext\&pi$\mathrm{d}=$ S1413-81232011001300010\& $=\mathrm{pt}$

165. Delgado PGG. Democracia e reforma psiquiátrica no Brasil. Cien Saude Colet 2011 [acessado 2020 Abr 06]; 16(12):4701-4706. Disponível em: http:// www.scielo.br/scielo.php?script=sci_arttext\&pi$\mathrm{d}=$ S1413-81232011001300019\&=pt

166. Mari JJ. Um balanço da Reforma Psiquiátrica Brasileira. Cien Saude Colet 2011 [acessado 2020 Abr 06]; 16(12):4593-4596. Disponível em: https:// www.scielo.br/scielo.php?script=sci_arttext\&pi$\mathrm{d}=$ S1413-81232011001300005

167. Lobosque AM. Debatendo alguns desafios da Reforma Psiquiátrica brasileira. Cien Saude Colet 2011 [acessado 2020 Abr 06]; 16(12):4590-4592. Disponível em: http://www.scielo.br/scielo.php?script=sci_arttext\&pid=S1413-81232011001300003\&=pt

168. Pinho LBD, Kantorski LP. Psychiatric care in the Brazilian context. Cien Saude Colet 2011 [acessado 2020 Abr 06]; 16(4):2107-2114. Disponível em: http:// www.scielo.br/scielo.php?script $=$ sci_arttext\&pi$\mathrm{d}=\mathrm{S} 1413-81232011000400010 \&=\mathrm{pt}$

169. Pitta AMF. Um balanço da reforma psiquiátrica brasileira: instituições, atores e política. Cien Saude Colet 2011 [acessado 2020 Abr 06]; 16(12):4579-4589. Disponível em: http://www.scielo.br/scielo.php?script=sci_arttext\&pid=S1413-81232011010600001\& $=$ pt

170. Ribeiro JM, Inglez-Dias A. Políticas e inovação em atenção à saúde mental: limites ao descolamento do desempenho do SUS. Cien Saude Colet 2011 [acessado 2020 Abr 06]; 16(12):4623-4634. Disponível em: http://www.scielo.br/scielo.php?script=sci_arttext\&pid=S1413-81232011001300011\&=pt 
171. Alves DS. Interview with Benedetto Saraceno by Domingos Sávio Alves. Cien Saude Colet 2011 [acessado 2020 Abr 06]; 16(12):4695-700. Disponível em: https://www.scielo.br/scielo.php?script=sci_arttext\&pi$\mathrm{d}=$ S1413-81232011001300018

172. Braz M, Schramm FR. Bioética e pesquisa em saúde mental. Cien Saude Colet 2011 [acessado 2020 Abr 06]; 16(4):2035-2044. Disponível em: http:// www.scielo.br/scielo.php?script $=$ sci_arttext\&pi$\mathrm{d}=\mathrm{S} 1413-81232011000400002 \&=\mathrm{pt}$

173. Onocko-Campos RT, Palombini AL, Leal E, Serpa Junior OD, Baccari IOP, Ferrer AL, Diaz AG, Xavier MAZ. Narrativas no estudo das práticas em saúde mental: contribuições das perspectivas de Paul Ricoeur, Walter Benjamim e da antropologia médica. Cien Saude Colet 2013 [acessado 2020 Abr 06]; 18(10):2847-2857. Disponível em: http:// www.scielosp.org/scielo.php?script=sci_arttext\&pi$\mathrm{d}=\mathrm{S} 1413-81232013001800009 \&=\mathrm{pt}$

174. Palombini AL, Onocko-Campos RT, Silveira M, Gonçalves LLM, Zanchet L, Xavier MAS, Marques CC. Relações entre pesquisa e clínica em estudos em cogestão com usuários de saúde mental. Cien Saude Colet 2013 [acessado 2020 Abr 06]; 18(10):2899-2908. Disponível em: http://www.scielo.br/scielo.php?scrip$\mathrm{t}=$ sci_arttext\&pid=S1413-81232013001000014\&=pt

175. Sade C, Barros LMR, Melo JJM, Passos E. O uso da entrevista na pesquisa-intervenção participativa em saúde mental: o dispositivo GAM como entrevista coletiva. Cien Saude Colet 2013 [acessado 2020 Abr 06]; 18(10):2813-2824. Disponível em: http:// www.scielo.br/scielo.php?script=sci_arttext\&pi$\mathrm{d}=\mathrm{S} 1413-81232013001000006 \&=\mathrm{pt}$

176. Nunes MDO, Torrenté MD. Abordagem etnográfica na pesquisa e intervenção em saúde mental. Cien Saude Colet 2013 [acessado 2020 Abr 06]; 18(10):2859-2868. Disponível em: http://www.scielo.br/scielo.php?scrip$\mathrm{t}=$ sci_arttext\&pid=S1413-81232013001000010\&=pt

177. Guimaro MS, Caiuby AVS, Santos OFP, Lacerda SS, Andreoli SB. Sintomas de estresse pós-traumático em profissionais durante ajuda humanitária no Haiti, após o terremoto de 2010. Cien Saude Colet 2013 [acessado 2020 Abr 06]; 18(11):3175-3181. Disponível em: http://www.scielo.br/scielo.php?script=sci_ arttext\&pid=S1413-81232013001100008\& $=\mathrm{pt}$

178. Baasch D, Trevisan RL, Cruz RM. Perfil epidemiológico dos servidores públicos catarinenses afastados do trabalho por transtornos mentais de 2010 a 2013. Cien Saude Colet 2017 [acessado 2020 Abr 06]; 22(5):1641-1650. Disponível em: http:// www.scielo.br/scielo.php?script=sci_arttext\&pi$\mathrm{d}=\mathrm{S} 1413-81232017002501641 \&=\mathrm{pt}$

179. Silva PFD, Costa NDR. Saúde mental e os planos de saúde no Brasil. Cien Saude Colet 2011 [acessado 2020 Abr 06]; 16(12):4653-4664. Disponível em: http:// www.scielo.br/scielo.php?script=sci_arttext\&pi$\mathrm{d}=$ S1413-81232011001300014\&=pt

180. Ribeiro FML, Minayo MCDS. O papel da religião na promoção da saúde, na prevenção da violência e na reabilitação de pessoas envolvidas com a criminalidade: revisão de literatura. Cien Saude Colet 2014 [acessado 2020 Abr 06]; 19(6):1773-1789. Disponível em: http://www.scielo.br/scielo.php?script=sci_arttex$\mathrm{t} \& \mathrm{pid}=$ S1413-81232014000601773\& $=\mathrm{pt}$
181. Leão LHDC, Gomez CM. The issue of mental health in occupational health surveillance. Cien Saude Colet 2014 [acessado 2020 Abr 06]; 19(12):4649-4658. Disponível em: http://www.scielo.br/scielo.php?script=sci_arttext\&pid=S1413-81232014001204649\&=pt

182. Padilha CDS, Oliveira WFD. Representação social do terapeuta comunitário na rede SUS. Cien Saude Colet 2013 [acessado 2020 Abr 06]; 18(8):2211-2220. Disponível em: http://www.scielo.br/scielo.php?script=sci_arttext\&pid=S1413-81232013000800005\&=pt

183. Abeldaño RA, Fernández R. Salud mental en la comunidad en situaciones de desastre. Una revisión de los modelos de abordaje en la comunidad. Cien Saude Colet 2016 [acessado 2020 Abr 06]; 21(2):431-442. Disponível em: http://www.scielo.br/scielo.php?scrip$\mathrm{t}=$ sci_arttext\&pid=S1413-81232016000200431\&=pt

184. Cavalcante FG, Minayo MCDS. Estudo qualitativo sobre tentativas e ideações suicidas com 60 pessoas idosas brasileiras. Cien Saude Colet 2015 [acessado 2020 Abr 06]; 20(6):1655-1666. Disponível em: http:// www.scielo.br/scielo.php?script=sci_arttext\&pi$\mathrm{d}=$ S1413-81232015000601655\& $=\mathrm{pt}$

185. Pacichana-Quinayáz SG, Osorio-Cuéllar GV, Bonilla -Escobar FJ, Fandiño-Losada A, Gutiérrez-Martínez MI. Common Elements Treatment Approach based on a Cognitive Behavioral Intervention: implementation in the Colombian Pacific. Cien Saude Colet 2011 [acessado 2020 Abr 06]; 21(6):1947-1956. Disponível em: http://www.scielosp.org/scielo.php?script=sci_ arttext\&pid=S1413-81232016000601947\& $\&=\mathrm{pt}$

186. Smolen JR, Araújo EMD. Raça/cor da pele e transtornos mentais no Brasil: uma revisão sistemática. Cien Saude Colet 2017 [acessado 2020 Abr 06]; 22(12):4021-4030. Disponível em: http:// www.scielo.br/scielo.php?script=sci_arttext\&pi$\mathrm{d}=$ S1413-81232017021204021\&=pt

187. Quadros LCM, Laura HC, Quevedo LA, Gigante DP. Efeitos da mobilidade social na saúde mental de adultos: uma revisão sistemática da literatura. Cien Saude Colet 2016 [acessado 2020 Abr 06]; 21(2):443-448. Disponível em: http://www.scielo.br/scielo.php?scrip$\mathrm{t}=$ sci_arttext\&pid=S1413-81232016000200443\& $\&=\mathrm{pt}$

188. Bonilla-Escobar FJ, Osorio-Cuellar GV, PacichanaQuinayáz SG, Sánchez-Rentería G, Fandiño-Losada A, Gutiérrez MI. Do not forget culture when implementing mental health interventions for violence survivors. Cien Saude Colet 2017 [acessado 2020 Abr 06]; 22(9):3053-3059. Disponível em: http:// www.scielo.br/scielo.php?script=sci_arttext\&pi$\mathrm{d}=$ S1413-81232017002903053\& $=\mathrm{pt}$

Artigo apresentado em 28/07/2020

Aprovado em 28/07/2020

Versão final apresentada em 30/07/2020 